\title{
Direct synthesis of dimethyl ether: A simulation study on the influence of the catalyst configuration
}

\author{
Giulia Baracchini ${ }^{\mathrm{a}, \mathrm{b}}$, Michael Klumpp ${ }^{\mathrm{a}, \mathrm{b}, *}$, Patrick Arnold ${ }^{\mathrm{a}}$, Roland Dittmeyer ${ }^{\mathrm{a}, \mathrm{b}}$ \\ a Institute for Micro Process Engineering, Karlsruhe Institute of Technology (KIT), Hermann-von-Helmholtz-Platz 1, 76344 Eggenstein-Leopoldshafen, Germany \\ ${ }^{\mathrm{b}}$ Institute of Catalysis Research and Technology, Karlsruhe Institute of Technology (KIT), Hermann-von-Helmholtz-Platz 1, 76344 Eggenstein-Leopoldshafen, Germany
}

\section{H I G H L I G H T S}

- Particulate and planar catalyst configurations are modelled for the STD reaction.

- A crystallite-pore network model is adapted to describe the catalytic configurations.

- For the different configurations, the accordant optimum catalyst ratio is presented.

- Porosity in structured catalysts strongly effects CO-conversion and DME-selectivity.

- Best performance by hybrid configurations of close proximity and planar double layer.

\section{Keywords:}

Hybrid catalyst

Bifunctional catalyst

Crystallite-pore network model

Anisotropic transport

Process intensification

\section{A B S T R A C T}

The direct synthesis of dimethyl ether (DME) from synthesis gas (STD) via methanol as an intermediate is a promising option for implementation of the Power-to-X concept, involving the storage of renewable electrical energy via hydrogen or synthesis gas in synthetic fuels or chemicals. The STD reaction shifts the equilibrium conversion dictated by thermodynamics to higher values compared to methanol synthesis alone at given conditions. Notwithstanding, proper catalyst materials and a suitable configuration have to be found that would support high CO-conversion as well as high DME-selectivity. In this work, different catalyst configurations obtained by combining $\mathrm{CuO} / \mathrm{ZnO} / \mathrm{Al}_{2} \mathrm{O}_{3}$ (CZA) for methanol synthesis with zeolite H-ZSM-5 (Z) for its dehydration are investigated via simulation based on a crystallite-pore network model, able to describe e.g. the polycrystalline anisotropic zeolite. In this way, hybrid particles with proximity of the two catalysts in both, the micrometer-scale (medium proximity, CZA + Z) and in the sub-micrometer-scale (close proximity, CZA\&Z) as well as structured core@shell particles (CZA@Z) were investigated for a tubular reactor. Moreover, their planar (coated) counterparts, namely the hybrid layered systems with medium (CZA\#Z) and close proximity (CZA\&/Z) and a structured double layer system $(\mathrm{CZA} / / \mathrm{Z})$ were investigated for a wall-coated microchannel reactor. The performance of these systems in the STD reaction was studied focusing on the influence of the CZA/Z ratio and the operational parameters (temperature, GHSV, feed composition). According to this study, hybrid particles with close proximity of the two catalysts as well as the double layer structures showed the best performance in terms of CO-conversion and DME-selectivity.

\footnotetext{
Abbreviations: $\mathrm{A}_{\text {cat }}{ }^{\text {cell }}$, catalyst area of the cell; $\mathrm{A}_{\text {cat }}{ }^{\text {mod }}$, modelled catalyst area; Bo, Bodenstein number; CPNM, crystallite-pore network model; CZA, CuO/ZnO/ $\mathrm{Al}_{2} \mathrm{O}_{3}$ catalyst; CZA + Z, hybrid particulate catalyst of medium proximity; CZA\&Z, hybrid particulate catalyst of close proximity; CZA@Z, CZA-core@zeolite-shell catalyst; CZA\#Z, hybrid planar catalyst of medium proximity; CZA\&/Z, hybrid planar catalyst of close proximity; CZA//Z, CZA-zeolite double layer catalyst; DME, Dimethyl ether; $f$ sc, scaling factor; GHSV, gas hourly space velocity; HC, hydrocarbons; MTD, methanol to DME; $\dot{N}_{i, \text { IN }}$, inlet molar flow of the component $I$; $\dot{N}_{i, \text { out }}$, outlet molar flow of the component $I ; \dot{N}_{i, \text { TR }}$, transfer molar flow of the component $i$; PFR, tubular plug flow reactor; $s$, dimensionless length coordinate; STD, synthesis gas to DME; STM, synthesis gas to methanol; TR, transfer; $y^{\prime}{ }_{\mathrm{CO}}$, dimensionless CO-concentration; $\mu$-CR, micro-channel reactor; $\omega_{\text {Zeo }}$ zeolite mass fraction

* Corresponding author at: Institute for Micro Process Engineering, Karlsruhe Institute of Technology (KIT), Hermann-von-Helmholtz-Platz 1, 76344 EggensteinLeopoldshafen, Germany.

E-mail address: michael.klumpp@kit.edu (M. Klumpp).
} 


\section{Introduction}

It is generally accepted that anthropogenic emissions of greenhouse gases are responsible for global warming and the consequent climate change occurring on our planet $[1,2]$. In order to limit its otherwise unavoidable effects, in 2015, by the Paris Agreement, the member states of the United Nations committed themselves to limiting the temperature rise to well below $2{ }^{\circ} \mathrm{C}$ compared to pre industrial levels [3]. In their special report "global warming of $1.5{ }^{\circ} \mathrm{C}$ ", in 2018 the Intergovernmental Panel on Climate Change emphasizes that the maximum increase in global temperature should rather be kept at $1.5^{\circ} \mathrm{C}$ above pre industrial levels at most to avoid drastic climate related consequences to, e.g., health, food security, water supply, and economic growth [4]. As outlined by the United Nations, in the European Union the emission in the transport sector even increased by $19.27 \%$ from 1990 until 2017 [5]. Therefore, it is of crucial importance to replace the conventional fossil sources in the production of fuels, that is why the European Commission defined the target to reach at least a share of $10 \%$ of transport fuels from renewable sources by 2020 and $14 \%$ in 2030 according to the 2009 [6] and 2018 [7] renewable energy di rectives, respectively. However, in 2050 as the latest, net zero in $\mathrm{CO}_{2}$ emissions should be reached in order to meet the $1.5{ }^{\circ} \mathrm{C}$ target [3].

As renewable power will be the most obvious energy source in a defossilized energy system by 2050, the straight forward fuel will be renewable power itself, i.e., e mobility. However, for certain transport sectors such as heavy duty transportation and long distance aviation, the high energy density of hydrocarbon fuels will also be needed in the future. Therefore, it is urgent to produce synthetic hydrocarbon fuels by innovative approaches, e.g., following the so called Power to $\mathrm{X}$ con cept, which involves the storage of electrical energy in chemical bonds, typically using water and $\mathrm{CO}_{2}$ as $\mathrm{H}$ and $\mathrm{C}$ sources, respectively [8,9]. The final product can be gaseous or liquid hydrocarbons or oxygenates (methane, Fischer Tropsch products, alcohols, ethers). These concepts permit the replacement of fuels or chemicals currently produced from fossil energy and allow the continued use of the existing infrastructure for storage, distribution and application. If the $\mathrm{CO}_{2}$ stems from the at mosphere and the energy needed for its conversion into fuels in the Power to X process is " $\mathrm{CO}_{2}$ free", a closed $\mathrm{CO}_{2}$ cycle is established $[10,11]$.

\subsection{Dimethyl ether in the Power to Fuel context}

Against this background, dimethyl ether (DME) synthesized from $\mathrm{CO}_{2}$ and renewable hydrogen is of great interest, as it can be used as a fuel, either directly in compression ignition engines, or after further processing as a substitute for fossil based gasoline (DME to Gasoline). In addition, DME is a valuable feedstock for the chemical industry (e.g. DME to Olefin) $[12,13,14]$. In the conventional process, DME is pro duced from synthesis gas $\left(\mathrm{CO} / \mathrm{H}_{2}\right)$ in two separate steps: first, the synthesis gas is converted over a Cu based catalyst into methanol (synthesis gas to methanol (STM), Eqs. 1 3), which is then dehydrated in a second step to DME over a solid acid catalyst, such as $\gamma \mathrm{Al}_{2} \mathrm{O}_{3}$ or zeolites (methanol to DME (MTD), Eq. (4)). In that approach CO con version in the STM reaction under typical operating conditions $\left(p=3050\right.$ bar; $T=200260{ }^{\circ} \mathrm{C}$ ) is limited by unfavorable thermo dynamic equilibrium, which calls for energy intensive recycling of large amounts of unreacted synthesis gas in the first step.

$\mathrm{CO}+2 \mathrm{H}_{2} \rightleftharpoons \mathrm{CH}_{3} \mathrm{OH}$

$\mathrm{CO}_{2}+3 \mathrm{H}_{2} \rightleftharpoons \mathrm{CH}_{3} \mathrm{OH}+\mathrm{H}_{2} \mathrm{O}$

$\mathrm{CO}+\mathrm{H}_{2} \mathrm{O} \rightleftharpoons \mathrm{CO}_{2}+\mathrm{H}_{2}$

$$
2 \mathrm{CH}_{3} \mathrm{OH} \rightleftharpoons \mathrm{CH}_{3} \mathrm{OCH}_{3}+\mathrm{H}_{2} \mathrm{O}
$$

However, if the two steps are combined in one single stage (one stage synthesis gas to DME (STD)), the thermodynamic equilibrium becomes more favorable and enables higher synthesis gas conversion as methanol is further reacted to DME and water. In addition to the in crease of per pass CO conversion, enhancing the DME selectivity can also contribute to increasing the space time yield, which is required in the context of Power to Fuel concept. Besides obtaining $\mathrm{CO}$ rich synthesis gas via e.g. co electrolysis, or reverse water gas shift reaction the possibility of direct activation of the $\mathrm{H}_{2} / \mathrm{CO}_{2}$ gas mixture to DME is nowadays in focus of several scientific studies such as, e.g. Refs. $[15,16,17]$. The interest of the scientific community in the direct uti lization of $\mathrm{CO}_{2}$, obtained with carbon capture technologies, is strongly growing. The thermodynamic stability of $\mathrm{CO}_{2}$ represents the hardest challenge to be overcome, demanding for new concepts and catalysts being able to reduce the energy demand of the process and reasonable degree of conversion [18]. Even if in literature CZA catalysts are re ported to be active for the methanol synthesis from $\mathrm{CO}_{2}$ (see i.e. Refs. $[16,17])$, higher methanol selectivity can be reached when applying $\mathrm{Cu} / \mathrm{ZnO} / \mathrm{ZrO}_{2}$ [19], $\mathrm{SiO}_{2}$ supported $\mathrm{Cu}$ nanoparticles [20] or novel $\mathrm{Pd}$ / In based materials [21].

In investigating the STD process, some issues are crucial and have been subject to several works available in the open literature. First, the choice of the proper arrangement of the two catalysts involved has been subject to several studies. In general, the STM and the MTD catalysts can be combined by using a (i) physical mixture on the reactor level $[22,23,24]$, a (ii) physical mixture on the pellet level $[17,25,26,27,28]$ and a (iii) structured bifunctional catalysts such as a core@shell con figuration [29,30,31,32,33,34] as well as synthesising at least one catalyst in the presence of the other one $[35,36,37]$. Second, the mass ratio of the two catalysts $\omega_{\mathrm{STM}} / \omega_{\mathrm{MTD}}$ has been investigated, as reported in Refs. [17,24,25,26,36,38,39]. Third, special attention should be given to the eventual deactivation of the catalyst due to the operating temperature, which should not overcome $270{ }^{\circ} \mathrm{C}[38,40,41,42,43]$, and the proximity of the active sites of type (ii) and (iii) [39,44,45,46]. Moreover, the generation of hydrocarbons as byproducts could also be an issue, as observed by some research groups [35,36,47,48,49]. All these aspects are described in detail in Supporting Information S1.1 S1.2.

Regarding the modelling and kinetics, several studies concern the individual STM $[50,51,52,53,54]$ and MTD $[55,56]$ stages as well as the STD process $[38,40,47,57,58,59]$. These studies are well summarized in Supporting Information S1.3.

In summary, several studies in literature have discussed the poten tial of bifunctional catalyst systems in the direct STD reaction based on different preparation principles and configurations of the catalyst(s). However, based on literature, deactivation effects must be considered when $\mathrm{Cu}$ based methanol synthesis catalysts are in close proximity to an acid dehydration catalyst. Therefore, experimentally determined reac tion performance data alone might be misleading when comparing different catalyst configurations. Furthermore, the production of side products (hydrocarbons) during the STD process have been reported at certain conditions by experimental works, which is why some authors included these side reactions in the modelling of the STD kinetics.

In order to quantify the effect of a certain catalyst configuration, in this contribution, modelling tools are used to evaluate the bare effect of the catalyst configuration (medium resp. close proximity in hybrid systems and structured bifunctional catalysts; pellet and layered sys tems) and composition independent of the aforementioned potential catalyst modification and deactivation caused by the material interac tions and without the influence of possible side reactions.

\section{Model development}

The aim of this work is to investigate the performance of certain catalyst configurations in the STD process in terms of CO conversion and DME selectivity in a tubular plug flow reactor (PFR) and a micro channel reactor $(\mu \mathrm{CR})$. The catalyst configurations investigated are the result of different possible combinations of $\mathrm{CuO} / \mathrm{ZnO} / \mathrm{Al}_{2} \mathrm{O}_{3}$ (CZA) for 


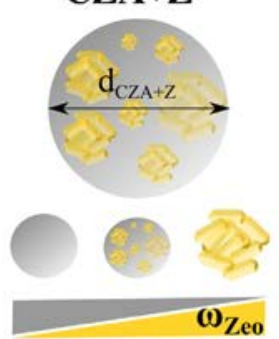

b

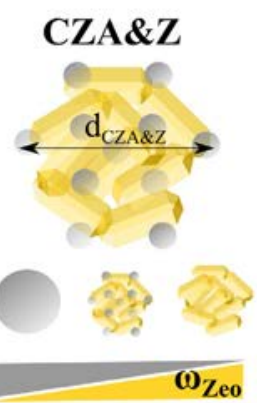

c
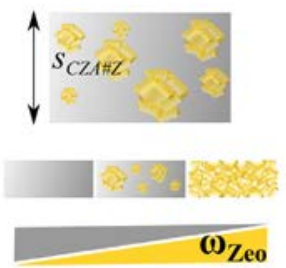

CZA\&/Z
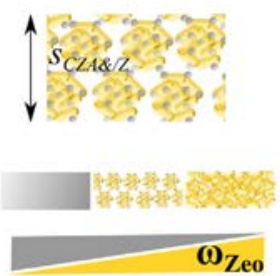

CZA $/ / \mathbf{Z}$
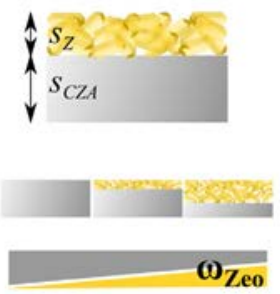
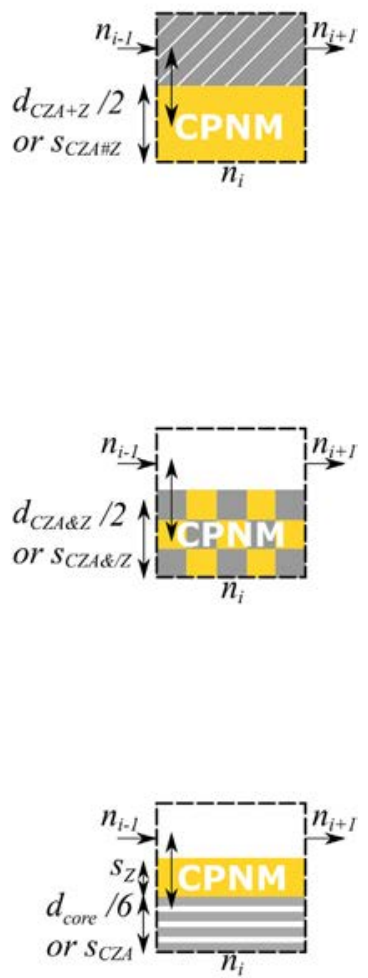

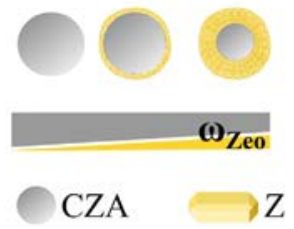

Fig. 1. Illustration of the catalyst configurations investigated. a) Hybrid configurations on the pellet/layer level with close proximity of the two catalysts in micrometer-scale, b) hybrid configurations with medium proximity of the two catalysts in sub-micrometer-scale and c) structured catalysts core@shell and double layer configurations. Simplified, the range of $\omega_{\text {Zeo }}$ investigated and the model of a cell used for the simulation thereof in the accordant reactor are shown.

the conversion of synthesis gas to methanol (STM) and zeolite H ZSM 5 (Z) for the subsequent dehydration of methanol to the desired product DME (MTD). These configurations cover both, particulate and planar (coated) systems implemented in PFR and $\mu$ CR, respectively. The cat alysts were classified based on the structural parameters originating from the synthesis procedure (details on the synthesis can be found in [60] and in the Supporting Information S1). Fig. 1 gives an overview on the different catalyst systems: first, hybrid particulate and planar sys tems with the two catalysts either in the micrometer scale (Fig. 1a, medium proximity: $\mathrm{CZA}+\mathrm{Z}$ and $\mathrm{CZA} \mathrm{Z}$ ) or in the sub micrometer scale (Fig. 1b, close proximity: CZA\&Z and CZA\&/Z); second, structured catalysts, namely the core@shell particulate system (Fig. 1c, CZA@Z) as well as its planar counterpart (Fig. 1c, CZA//Z). In this context it is important to mention that for the hybrid systems with a medium proximity (in the micrometer scale), namely CZA $+\mathrm{Z}$ and CZA\#Z, the arrangement of the CZA and zeolite cannot be controlled during the preparation (see (ii) in Section 1.1), while for the hybrid systems with close proximity (in the sub micrometer range), namely CZA\&Z and CZA \&/Z, and especially for CZA@Z and CZA//Z, the arrangement of the two catalytic species is predefined by the preparation principle applied (see (iii) in Section 1.1). Moreover, while the purpose of the CZA@Z system is to enwrap the CZA core with a dense zeolitic membrane (see also details in [60]) in order to maximize DME selectivity, in case of the coated CZA//Z the upper layer should consist of a non dense zeolitic film, aiming to enhance the diffusion of the reactants. Therefore, even if the arrangement of the two structures follows a similar approach in either a spherical (CZA@Z) or planar (CZA//Z) geometry, the specific concepts differ in the purpose of the zeolite layers' properties and in the preparation principles applied (see also Supporting Information S1).

Starting from the material properties obtained from the character ization of the synthesized catalysts and the description of the transport processes and the kinetics thereof, the catalytic configurations were compared in terms of the influence of the CZA/zeolite mass ratio (ex pressed as zeolite mass fraction $\omega_{\mathrm{Zeo}}$ ) and the process parameters (temperature, gas hourly space velocity (GHSV), feed composition) on the catalytic performance, i.e. CO conversion and product selectivity. All the catalyst structures considered as well as the range of CZA/zeolite mass ratio investigated and the implementation of the model thereof are schematically represented in Fig. 1.

\subsection{The catalysts investigated}

In this work CZA and zeolite $\mathrm{H}$ ZSM $5(\mathrm{Si} / \mathrm{Al}$ ratio $=50)$ catalysts, prepared via flame spray pyrolysis and hydrothermal synthesis, re spectively, were considered. In recent publications CZA@Z and $C Z A+Z$ have been synthesized $[60,61]$, the preparation procedure of CZA\&Z, CZA\#Z and CZA//Z is reported in the Supporting Information $\mathrm{S} 2, \mathrm{CZA} \& / \mathrm{Z}$ is considered theoretically in the present study.

In order to describe both, the anisotropy of the zeolite ZSM 5 (MFI type zeolite) pore structure as well as the polycrystallinity of the MTD catalyst system, the 3D crystallite pore network model (3D CPNM) was applied (see [62] for details). In brief, following this model, the MTD 
catalyst (i.e. zeolite) is built up by the three dimensional arrangement of three kinds of nodes (zeolite crystal, interface nodes and inter crystalline nodes) and two kinds of connections (zeolitic micropores and intra or intercrystalline pores, e.g. originating from defects within the zeolite crystal or the layer, respectively). Each zeolitic crystal node is connected through a zeolitic micropore to an interface node, which is also connected to an intercrystalline node via a defect pore (either intra or intercrystalline). The connectivity was introduced to define the connection between the intercrystalline and the interface nodes, giving the average number of the intercrystalline nodes connected with a second node (either intercrystalline or interface). In order to implement the orientation of the crystals in the 3 dimentional space, the angles $\psi$ and $\chi$ are defined to describe the rotation of the crystal with respect to the $x y$ and $x z$ planes in the $x y z$ coordinate system, respectively $[61,62]$.

In general, the 3D CPNM enables a description of the poly crystallinity and anisotropy of the zeolite and allows for an evaluation of the influence of the zeolite properties (porosity, layer thickness, etc. resulting from, e.g., synthesis parameters) on the STD reaction when being part of a bifunctional catalyst system, namely when the CZA is also included in the model. The CZA catalyst was added in the model with certain assumptions for each configuration (see Sections 2.1.1 and 2.1.2). In general, the connection between an interface node and a zeolite crystal does always apply micropore properties, while the con nection between an interface node to a CZA particle always applies intercrystalline pores. This general description was applied to each catalyst configuration, and particular attention was paid to the hybrid structures of close proximity, where the STM catalyst was introduced in a matrix of H ZSM 5 nanocrystals (see Section 2.1.1). For the hybrid structures of medium proximity as well as for the structured bifunc tional catalysts, due to the assumptions made and to the catalyst con figuration, the CZA particles are confined in the accordant zones of the catalyst only. Therefore, the diffusion of the reactants within the cat alyst system and the reaction rates for STM and MTD have to be im plemented. For each configuration considered in this work, the same specific material parameters obtained from the characterization of the individual catalysts used and from literature have been applied the material parameters common to each configuration either extracted from literature or obtained from characterization are listed in Table 1. In order to represent the different catalyst configurations in a way that they could potentially be used in real applications and to obtain structural parameters crucial for the systematic modelling, model cat alysts have been prepared and characterized in recent studies $[60,61]$. Details on the characteristics of the individual catalyst systems in vestigated are given in the following sections. Further results on the materials are summarized in the Supporting Information S2.

\subsubsection{Hybrid catalyst systems}

Hybrid catalysts of medium proximity on the pellet/layer level (CZA $+\mathrm{Z}$ and CZA\#Z, respectively) as well of close proximity as par ticulate/coated system (CZA\&Z and CZA\&/Z, respectively) were con sidered (see Fig. 1). Details about the preparation procedure are given in the Supporting Information S2. The more intimate proximity be tween CZA and zeolite in the hybrid systems CZA\&Z and, thus, CZA\&/Z

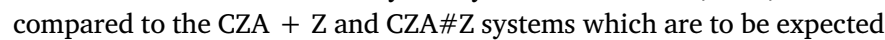
according to the preparation procedure could also be observed by

Table 1

Parameters used for the modelling of each bifunctional catalyst.

\begin{tabular}{llll}
\hline Parameter & Unit & Value & Source \\
\hline CZA skeletal density & $\mathrm{kg}^{3} \mathrm{~m}^{1}$ & 3890 & Hg-porosimetry \\
H-ZSM-5 skeletal density & $\mathrm{kg}^{3} \mathrm{~m}$ & 1835 & {$[62]$} \\
H-ZSM-5 micropore diameter & $\mathrm{nm}$ & 0.56 & {$[63]$} \\
H-ZSM-5 mesopore diameter & $\mathrm{nm}$ & 16 & $\mathrm{~N}_{2}$-physisorption \\
H-ZSM-5 microporosity & vol.-\% & 10 & {$[62]$} \\
\hline
\end{tabular}

Table 2

Parameters used for the modelling of the hybrid catalyst configurations of medium proximity (CZA $+\mathrm{Z}$ and CZA\#Z).

\begin{tabular}{llll}
\hline Parameter & Unit & \multicolumn{2}{l}{ Value } \\
\cline { 3 - 4 } & & CZA $+\mathrm{Z}$ & CZA\#Z \\
\hline H-ZSM-5 crystal size & $\mathrm{nm}$ & 51 & 51 \\
H-ZSM-5 intercrystalline porosity & vol.- $\%$ & 64 & 54 \\
CZA meso- and macro-porosity & vol.- $\%$ & 50 & 50 \\
CZA size & $\mathrm{nm}$ & 10 & 10 \\
CZA + Z pellet size & $\mu \mathrm{m}$ & 75 & - \\
CZA\#Z layer thickness & $\mu \mathrm{m}$ & - & 60 \\
\hline
\end{tabular}

microscopy (TEM and EPMA) as summarized in the Supporting Information $\mathrm{S} 2$.

For the modelling, all hybrid particulate $(C Z A+Z, C Z A \& Z)$ and layered (CZA\#Z, CZA\&/Z) catalyst configurations were approximated as a layer (see Fig. 1, right), with a height equal to the radius of the particulate systems (rotational symmetry) and the actual thickness of the coating, respectively. Details on the structural parameters of all the different hybrid configurations considered are given below. According to the potential application of the catalysts, the particulate CZA $+\mathrm{Z}$, CZA\&Z configurations were investigated for a tubular plug flow reactor (PFR), while the planar CZA\#Z and CZA\&/Z configurations were con sidered for micro channel reactors $(\mu \mathrm{CR})$.

2.1.1.1. Hybrid catalyst configurations of medium proximity $(C Z A+Z$ and $C Z A \# Z$ ). Table 2 summarizes the parameters obtained from the characterization and implemented for the CZA $+\mathrm{Z}$ and the CZA\#Z systems.

As reported in the work of Ding [61], the mass transport resistance within the CZA catalyst can be neglected compared to the zeolite mi cropores. Building on this, both the CZA $+\mathrm{Z}$ and the CZA\#Z hybrid systems were implemented into the model by assuming a homogeneous distribution of the CZA catalyst in the gas phase and describing only the H ZSM 5 by the 3D CPNM. In this way, for the CZA the STM reaction rate was applied for the bulk gas phase conditions, while for the zeolite besides the MTD reaction rate also the diffusion was considered.

2.1.1.2. Hybrid catalyst configurations of close proximity (CZA\&Z and $C Z A \& / Z$ ). For the modelling of the hybrid configurations of close proximity, both as particulate and coated system, the CZA\&Z and CZA\&/Z catalysts were considered as a matrix of H ZSM 5 nanocrystals with the nanosized CZA catalyst being situated within the non zeolitic pores at the intercrystalline nodes in the 3D CPNM of the zeolite matrix, which is in accordance with the TEM images of the synthetized particles (see also Fig. S2 in the Supporting Information). The total mass of CZA situated in the zeolite matrix was predetermined by the chosen $\omega_{\mathrm{STM}} / \omega_{\mathrm{MTD}}$ ratio. The structural parameters obtained from the characterization of the particulate system and used in the model are summarized in Table 3. The STM reaction rate was referred to the mass of CZA present at the considered node, the dehydration reaction rate was referred to the mass of the zeolite and connected to the nodes representing the zeolitic crystals. The same assumptions were used for

Table 3

Parameters used for the modelling of the hybrid catalyst configurations of close proximity (CZA\&Z and CZA\&/Z).

\begin{tabular}{lll}
\hline Parameter & Unit & Value \\
\hline H-ZSM-5 crystal size & $\mathrm{nm}$ & 51 \\
CZA size & $\mathrm{nm}$ & 10 \\
H-ZSM-5 intercrystalline porosity & vol.-\% & 32 \\
CZA\&Z particle size & $\mathrm{nm}$ & 400 \\
CZA\&/Z layer thickness & $\mu \mathrm{m}$ & 60 \\
\hline
\end{tabular}


Table 4

Parameters used for the modelling of the core@shell (CZA@Z) and double layer (CZA//Z).

\begin{tabular}{llll}
\hline Parameter & Unit & \multicolumn{2}{l}{ Value } \\
\cline { 3 - 4 } & & CZA@Z & CZA//Z \\
\hline H-ZSM-5 crystal size & $\mu \mathrm{m}$ & 2 & 2 \\
H-ZSM-5 intercrystalline porosity & vol.- $\%$ & 0.1 & 32 \\
CZA mesoporosity & vol.- $\%$ & 50 & 50 \\
CZA core diameter & $\mu \mathrm{m}$ & 72 & - \\
H-ZSM-5 shell thickness & $\mu \mathrm{m}$ & $2-50$ & - \\
CZA layer thickness & $\mu \mathrm{m}$ & - & 20 \\
H-ZSM-5 layer thickness & $\mu \mathrm{m}$ & - & $2-50$ \\
\hline
\end{tabular}

the modelling of the correspondent hybrid layered system CZA\&/Z.

\subsubsection{Structured core shell (CZA@Z) and double layer (CZA//Z) systems}

Structured catalysts with a dedicated ordering of the two individual catalysts were investigated in spherical (CZA@Z) and planar (CZA//Z) configuration. The synthesis of the CZA@Z catalyst was reported else where $[60,61]$. The coating procedure of the double layer structure $\mathrm{CZA} / / \mathrm{Z}$ is described in the Supporting Information S2. According to previous work, as the zeolitic shell in the CZA@Z configuration is much thinner than the diameter of the CZA core, the CZA@Z system can be approximated as a planar double layer and modelled comparable to the $\mathrm{CZA} / / \mathrm{Z}$ configuration [61]. For this geometric transformation, the shell thickness was varied in the simulation, while the thickness of the CZA layer was predefined by converting the core diameter of the actual catalyst by $d_{\text {CZA core }} / 6$, in order to obtain the same CZA/H ZSM 5 vo lumetric ratio in the model as present in the actual spherical CZA@Z catalyst. The structural parameters of CZA//Z and CZA@Z catalysts are listed in Table 4.

After the aforementioned transformation of the CZA@Z from spherical to planar geometry, the same assumptions for both structured configurations were applied: as already mentioned in Section 2.1, due to the given pore structure, the diffusion of each gas species is much faster in the CZA catalyst than in the H ZSM 5. Therefore, following the method of Ding et al., for the modelling of the double layer systems the CZA catalyst was discretized into 4 layers, while the H ZSM 5 layer was described by the 3D CPNM [61]. In the CZA@Z system, H ZSM 5 shell thicknesses of up to $50 \mu \mathrm{m}$ covering CZA core diameters of up to $72 \mu \mathrm{m}$ were modelled corresponding to $\omega_{\text {Zeo }}=656 \mathrm{wt} \%$. In the $\mathrm{CZA} / / \mathrm{Z}$ system, CZA and H ZSM 5 layers of $20 \mu \mathrm{m}$ and $250 \mu \mathrm{m}$, respectively, were considered, corresponding to $\omega_{\mathrm{Zeo}}=240 \mathrm{wt} \%$.

The CZA@Z system was investigated as a packed bed of particles in a PFR, while the CZA//Z was implemented as a wall coating in a $\mu \mathrm{CR}$.

\subsection{Reactor modelling}

As mentioned, in this study several catalyst configurations were implemented in two different reactors: the tubular plug flow reactor (PFR) with a packed bed for particulate systems and the micro channel reactor ( $\mu \mathrm{CR}$ ) for coated catalyst layers. The following assumptions concerning the ideal behavior of both reactors were applied:

- absence of axial dispersion (Bo > 100);

- negligible radial and axial temperature gradients in the catalyst bed resp. layer;

- absence of external heat and mass transport limitations;

- absence of intraparticle temperature gradients.

All the hypotheses were proven experimentally and by calculation according to the criteria discussed in the work of Tauro, who in vestigated the STD reaction in mixed catalyst beds in both types of reactors [64]. These assumptions were accepted in order to evaluate the
Table 5

Dimensions of the PFR and $\mu$-CR.

\begin{tabular}{llllll}
\hline PFR & \multicolumn{5}{c}{$\mu$-CR } \\
\hline Parameter & Unit & Value & Parameter & Unit & Value \\
\hline $\begin{array}{c}\text { Catalyst bed } \\
\text { length } \\
\begin{array}{c}\text { Reactor } \\
\text { diameter }\end{array}\end{array}$ & $\mathrm{cm}$ & 9.5 & micro-channel length & $\mathrm{cm}$ & 15 \\
\hline
\end{tabular}

effect of the catalyst configuration only, even though temperature profile along the reactor, which, in general, challenges the STD process due to its exothermicity and consequent potential hot spot formation, might occur in practical application depending on the thermal man agement of the reactor considered. In this context, it should be em pathized that microstructured reactors are well known to allow a very efficient removal of heat, as reported in several studies $[15,16,65,66,67]$ and, thus, allow for almost isothermal conditions. The dimensions of the two reactors are given in Table 5. For the description of the mass transport in the PFR and the $\mu \mathrm{CR}$, the common definitions of dimensional analyses according to Ref. [68] were applied (see Supporting Information S3).

For the simulation, both reactors had to be discretized. The PFR and the $\mu \mathrm{CR}$ were discretized with respect to its total length and to the length of one channel, respectively: the length of the reactor (i.e. length of the tube or channel) was divided into a number of cells $\left(N_{\text {Rea }}\right)$ of the same length $(\Delta x)$. In each cell $n_{i}$, the gas phase was considered as ideally mixed and the catalyst was described according to the considerations discussed in Section 2.1. Composition and flow rates of the gas phase at the outlet from the cell $n_{i}$ were used as the inlet of the following cell $n_{i}$ ${ }_{+1}$. It was proven that $N_{\text {Rea }}=100$ enabled a precise description of the reactor within reasonable computational time (the results do not change for $N_{\text {Rea }}>100$ ). For the calculation of the mass transfer be tween the gas phase and the catalyst within each cell, in order to save computational time, the model considered a fraction $A_{\text {cat }}^{\text {mod }}$ of the total catalyst surface area within each cell $\left(A_{\text {cat }}^{\text {cell }}\right)$. Therefore, a scaling factor $\left(f_{\text {sc }}\right)$ was defined according to Eq. (5). Eq. (6) represents the component balance of the cell $n_{i}$, where $\dot{N}_{i, \mathrm{TR}}$ represents the transfer molar flow between the gas phase and the catalyst, which depends on the diffusion and reaction calculated from the catalyst model (see Eq. (7)).

$f_{\mathrm{sc}}=A_{\text {cat }}^{\text {cell }} / A_{\text {cat }}^{\text {mod }}$

$\dot{N}_{i, \text { IN }}-\dot{N}_{i, \text { OUT }}+\dot{N}_{i, \text { TR }}=0$

with

$\dot{N}_{i, \mathrm{TR}}=\dot{N}_{i, \mathrm{TR}}^{\text {cell }}=f_{\mathrm{sc}} \cdot \dot{N}_{i, \mathrm{TR}}^{\mathrm{mod}}$

\subsection{Diffusion}

The diffusion of all the components involved in the STD reaction for the CZA@Z system was described by Ding in Ref. [62]. On this basis, in the present work the considerations made by Ding were applied to all the bifunctional catalyst configurations. In brief, the mass transport in the intercrystalline zeolitic pores as well as in the CZA catalyst can be described by the Knudsen diffusion model, which is to be used when the mean free path length of a gas molecules is in the same range as the pore diameter and hence molecule wall collisions dominate over mo lecule molecule collisions [69]. In the micropores of the H ZSM 5 crystals, diffusional transport takes place predominantly in adsorbed state (surface diffusion), where interactions between molecules and adsorption sites as well as among different adsorbed molecules have to be considered [69]. In doing so, the diffusion of each component in the $x, y$ and $z$ directions can be described $[61,62]$. For the CZA\&Z as well as for the layered configurations CZA\&/Z and CZA//Z, the diffusion in 
the CZA catalyst was also considered. Due to the modelling concept of the CZA $+\mathrm{Z}$ and CZA\#Z systems described in Section 2.1, for these latter two configurations the diffusion in the CZA was neglected. This hypothesis is in line with what was reported by Ding et al., who showed that a discretization of the CZA into only 4 layers for the CZA@Z system lead to an absolute difference of species concentrations throughout the core of $<1 \%[61]$.

\subsection{Reactions kinetics}

In order to investigate the influence of the catalyst configuration and the STD process parameters on CO conversion and DME selectivity, both diffusion and reaction have to be considered and solved simulta neously. For all the modelling results discussed in this work, the STM kinetics implemented was taken from the recent study of Seidel et al. [52]. For the methanol dehydration reaction over H ZSM 5, the kinetics determined in previous works of Tauro and Ding was used [61,64].

In general, diffusion and reaction were solved with the 3D CPNM. Only in the cases of the CZA $+\mathrm{Z}$ and CZA\#Z, due to the assumptions of these hybrid catalysts (see Section 2.1.1), the component balance in the gas phase included also the STM reaction (see Eq. (8)).

$\dot{N}_{i, \mathrm{IN}}-\dot{N}_{i, \text { OUT }}+\dot{N}_{i, \text { TR }}+m_{\mathrm{CZA}} \nu_{i} r_{i}=0$

\subsection{Implementation of the model in MatLab ${ }^{\oplus}$}

The simulation of diffusion and reaction for the different catalyst configurations in the accordant reactor system (PFR or $\mu \mathrm{CR}$ ) was per formed via MatLab ${ }^{\circledast}$ for different process conditions ( $T$, GHSV, feed composition) and catalyst parameters $\left(\omega_{\mathrm{STM}} / \omega_{\mathrm{MTD}}\right)$. A detailed de scription of the individual steps of the simulation is given in the Supplementary Information S3.

The conversion of $\mathrm{CO}\left(X_{\mathrm{CO}}\right)$ resp. $\mathrm{CO}$ and $\mathrm{CO}_{2}$ together $\left(X_{\mathrm{CO} x}\right)$, the selectivity towards methanol and DME (indicated as $S_{i, \mathrm{CO} x}$ with respect to carbon conversion) as well as towards $\mathrm{CO}_{2}$ (indicated as $S_{\mathrm{CO} 2 \text {,CO }}$ with respect to $\mathrm{CO}$ conversion) were calculated according Eqs. 912 (see also [60]). In this way, $S_{\mathrm{DME}}+\mathrm{S}_{\mathrm{MeOH}}=100 \% \forall \omega_{\mathrm{Zeo}}$ and the values are not falsified by the consumption of $\mathrm{CO}_{2}$ at high $\omega_{\text {Zeo }}$ (see discussion in Section 3.1). The DME yield ( $\left.Y_{\mathrm{DME}}\right)$ and the DME productivity $\left(P_{\mathrm{DME}}\right)$ were calculated according to Eqs. 1314.

$$
\begin{aligned}
& X_{\mathrm{CO}}=1-\dot{N}_{\mathrm{CO}, \mathrm{OUT}} / \dot{N}_{\mathrm{CO}, \mathrm{IN}} \\
& X_{\mathrm{CO}_{\mathrm{x}}}=1-\left(\dot{N}_{\mathrm{CO}, \mathrm{OUT}}+\dot{N}_{\mathrm{CO}_{2}, \mathrm{OUT}}\right) /\left(\dot{N}_{\mathrm{CO}, \mathrm{IN}}+\dot{N}_{\mathrm{CO}_{2}, \mathrm{IN}}\right) \\
& S_{i, \mathrm{CO}_{\mathrm{x}}}=v_{i}\left(\dot{N}_{i, \mathrm{OUT}}-\dot{N}_{i, \mathrm{IN}}\right) /\left[\left(\dot{N}_{\mathrm{CO}, \mathrm{IN}}+\dot{N}_{\mathrm{CO}_{2}, \mathrm{IN}}\right)-\left(\dot{N}_{\mathrm{CO}},\right.\right. \\
& S_{\mathrm{CO}_{2}, \mathrm{CO}}=\left(\dot{N}_{\mathrm{CO}_{2}, \mathrm{OUT}}-\dot{N}_{\mathrm{CO}_{2}, \mathrm{IN}}\right) /\left(\dot{N}_{\mathrm{CO}, \mathrm{IN}}-\dot{N}_{\mathrm{CO}, \mathrm{OUT}}\right) \\
& Y_{\mathrm{DME}}=2 \dot{N}_{\mathrm{DME}, \mathrm{OUT}} /\left(\dot{N}_{\mathrm{CO}, \mathrm{IN}}+\dot{N}_{\mathrm{CO}_{2}, \mathrm{IN}}\right) \\
& P_{\mathrm{DME}}=\dot{N}_{\mathrm{DME}, \mathrm{OUT}} / m_{\mathrm{CAT}}
\end{aligned}
$$$$
S_{i, \mathrm{CO}_{\mathrm{x}}}=v_{i}\left(\dot{N}_{i, \text { OUT }}-\dot{N}_{i, \mathrm{IN}}\right) /\left[\left(\dot{N}_{\mathrm{CO}, \mathrm{IN}}+\dot{N}_{\mathrm{CO}_{2}, \mathrm{IN}}\right)-\left(\dot{N}_{\mathrm{CO}, \text { OUT }}+\dot{N}_{\mathrm{CO}_{2}, \mathrm{OUT}}\right)\right]
$$

Based on detailed studies on the individual effects of reaction temperature, feed gas composition, and GHSV (see Section 3.2 3.4), the following parameters have been fixed for all simulations aiming to compare the sole effect of catalyst configuration: feed gas composition: $\mathrm{H}_{2} / \mathrm{CO} / \mathrm{CO}_{2}=16 / 8 / 1,10$ vol $\% \mathrm{~N}_{2}$, reaction temperature: $250{ }^{\circ} \mathrm{C}$, GHSV $=2000 \mathrm{~mL} \mathrm{~h}^{-1} \mathrm{~g}_{\mathrm{CAT}}^{1}$. The GHSV was set to the same feed per total catalyst mass, as the amount of catalyst is predetermined by the reactor volume and, thus, has to be the same in order to compare dif ferent catalyst configurations for potential implementation. As being commonly used, absolute pressure was set to 40 bar.

\section{Results and discussion}

Superimposing limitations at the process conditions chosen can be ruled out for both the PFR and the $\mu$ CR: the performance of the reac tion system is affected by the configuration of the catalyst only (see Supporting Information S4). Based on this, in Section 3.1, the STD performance in terms of the CO conversion and product selectivity is compared among the different bifunctional catalyst systems differing in their configuration. In Section 3.2 3.4, the influence of the operational parameters will be discussed.

\subsection{Influence of the catalyst configuration and its composition}

The STD performance of the different bifunctional catalyst config urations with particular focus on the influence of the $\omega_{\text {Zeo }}$ for each configuration was investigated, in order to determine the optimal composition for each system in terms of maximum CO conversion and/ or the DME selectivity. It should be emphasized that only the results showing a maximum in the CO conversion significantly away from the STD equilibrium $\left(X_{\mathrm{CO}, \mathrm{STD}}\right.$ equi. $=93.8 \%$ at the predefined process conditions) were considered, in order to rule out erroneous conclusions affected by thermodynamics. While for the hybrid and double layer configurations, the amount of zeolite can be defined freely due to the preparation principle (see also Section 1.2), in the CZA@Z catalyst system $\omega_{\text {Zeo }}$ is predetermined by the shell thickness which can be achieved by the synthesis procedure applied: due to the concept and the synthesis of such catalysts, shell thickness of $>10 \mu \mathrm{m}$, corresponding to $\omega_{\text {Zeo }}=4 \mathrm{wt} \%$, is meaningful for the modelling in order to get a deeper insight in such catalyst systems but do not necessarily reflect a feasible catalyst, as also discussed in [60]. Thus, in the present study shell thickness up to $50 \mu \mathrm{m}$ covering a core catalyst of $72 \mu \mathrm{m}$ in diameter was considered.

Fig. 2 shows the $\mathrm{CO}$ conversion and the DME, methanol and $\mathrm{CO}_{2}$ selectivity versus $\omega_{\text {Zeo }}$ for the particulate configurations CZA\&Z, CZA + Z and CZA@Z in the PFR.

In general, the trend of the CO conversion for each of the three configurations shows a maximum, which is sufficiently below the CO equilibrium conversion of the STD reaction and does not show a pla teau, for which reason, at the operational conditions considered, ther modynamic limitations can be excluded. At low $\omega_{\mathrm{Zeo}}$, the CO conver sion is close to the STM equilibrium $\left(X_{\mathrm{CO}, \mathrm{STM}}\right.$ equi. $\left.=39.1 \%\right)$, before increasing with higher amount of zeolite until reaching a maximum. With further increase of $\omega_{\text {Zeo }}$, CO conversion drops and falls even below the STM equilibrium conversion at a certain composition. The maxima differ largely in value and to a somewhat lesser extent also in position for the different catalyst configurations. The higher the maximum the higher the value of $\omega_{Z e o}$ where it occurs. These general trends can be explained as follows: an excess of CZA catalyst (low $\omega_{\text {Zeo }}$ ) results in a limitation of the CO conversion by the STM equilibrium as the high $\mathrm{CZA} /$ zeolite ratio in the catalyst does not allow for a sufficiently fast dehydration of the methanol formed by the CZA to overcome this limitation. Upon increasing $\omega_{\text {Zeo }}$, the dehydration gets accelerated and methanol formation decelerated, and in turn CO conversions beyond the STM equilibrium become possible. This effect increases with in creasing value of $\omega_{\text {Zeo }}$ until a maximum value predetermined by the ratio of the methanol formation rate versus the methanol dehydration rate is reached. This ratio apparently depends on the catalyst config uration. The highest maximum is predicted for the hybrid catalyst with close proximity of the two components. The lowest maximum is ob served for the core@shell system. The hybrid catalyst with medium proximity takes an intermediate position. An increase in $\mathrm{CO}$ conversion can be attributed to two effects: firstly, an enhanced diffusion of the reactants through the regions of microporous zeolite and secondly an intimate contact between the two catalyst species. The hybrid particle systems get advantage in performing higher CO conversions due to the higher intercrystalline porosity of the zeolite compared to the core@ shell configuration (see Tables 2 4), thus, allowing for an enhanced diffusion of the species. Beside this, the proximity in the sub micro meter scale of the CZA\&Z catalyst increases the probability for the 

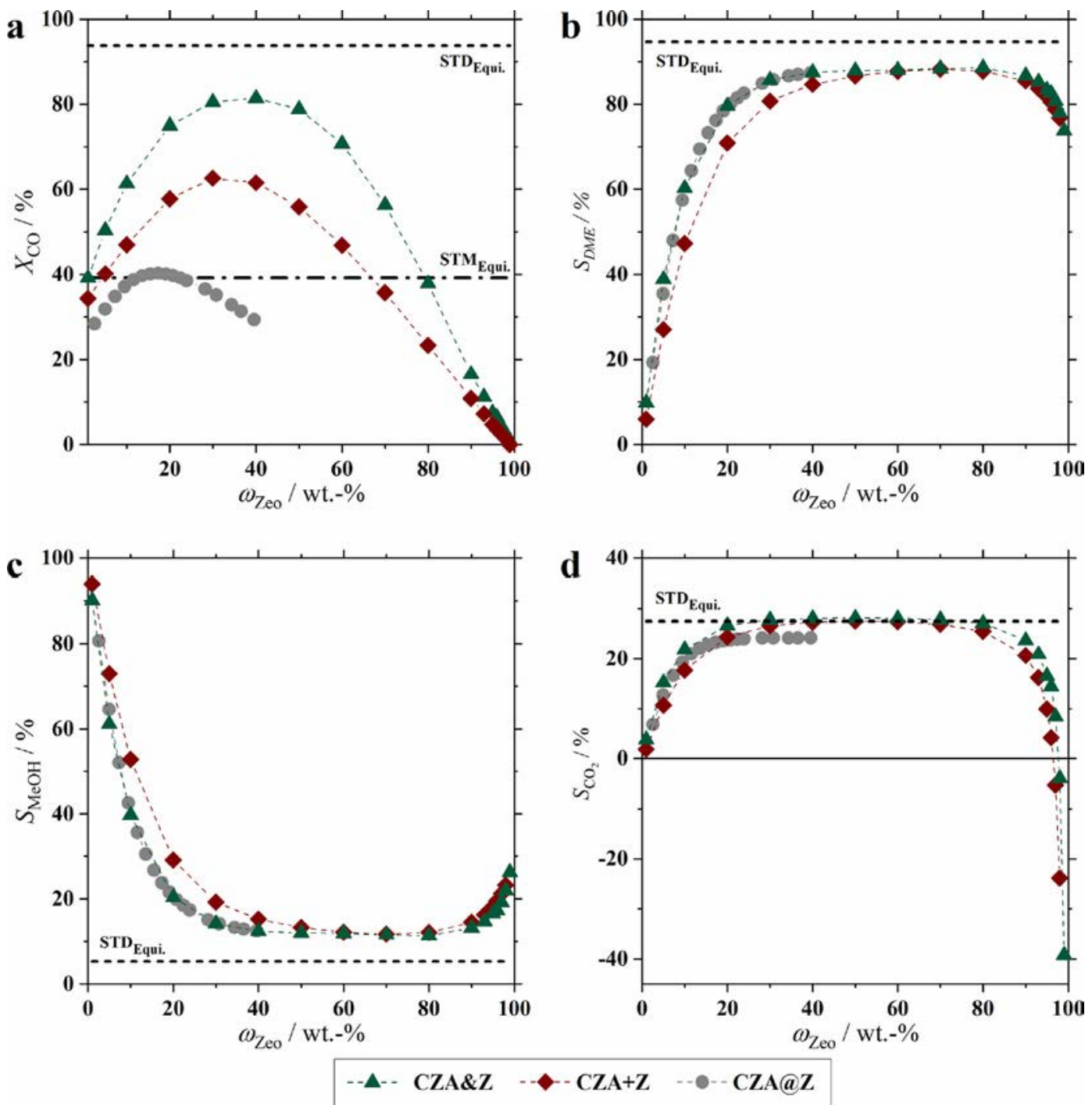

Fig. 2. a) CO-conversion $\left(X_{\mathrm{CO}}\right)$, b) DME-, c) methanol- and d) $\mathrm{CO}_{2}$-selectivity $\left(S_{\mathrm{DME}}, S_{\mathrm{MeOH}}\right.$ and $\left.S_{\mathrm{CO} 2}\right)$ for the particulate catalyst systems CZA\&Z, CZA $+\mathrm{Z}$ and CZA@ $\mathrm{Z}$ in a PFR. Reaction conditions: $p=40 \mathrm{bar}, T=250{ }^{\circ} \mathrm{C}, \mathrm{GHSV}=2000 \mathrm{~mL} \mathrm{~h}^{-1} \mathrm{~g}_{\mathrm{CAT}}^{1}$.

methanol to be dehydrated by the zeolite, namely the thermodynamic benefit is more pronounced as compared to the situation in the CZA $+\mathrm{Z}$ particles of medium proximity, where the two catalyst species are more segregated. The diffusion limitation caused by the zeolite shell (dense zeolitic membrane in the present study), counteracts the $\mathrm{CO}$ conversion in case of the CZA@Z system. These aspects will be object of further discussion. Beyond the maximum found for all three systems, CO conversion drops with increasing $\omega_{\text {Zeo }}$ as it gets limited kinetically by the scarce amount of CZA rather than thermodynamically by the STM equilibrium.

This qualitative interpretation of the result shown in Fig. 2a re garding the $\mathrm{CO}$ conversion can be mirrored for the discussion of the product selectivity. Three different regimes of $\omega_{\text {zeo }}$ are visible: for $\omega_{\text {Zeo }}<40 \mathrm{wt} \%$, DME selectivity increase with increasing $\omega_{\text {Zeo }}$ and, consequently, the methanol selectivity decreases. Here, the beneficial effect of coupling the STM with the dehydration reaction is most no table, as $\frac{\partial X_{\mathrm{CO}}}{\partial \omega_{\mathrm{Co}}}$ is the largest in this regime. Again, the system with close proximity is expected to perform better than the one with medium proximity, as indicated by higher DME and lower methanol selectivity. Interestingly, the core@shell system behaves exactly like the one with close proximity regarding selectivity (see discussion below). The curves show a maximum of the DME selectivity and a minimum for the me thanol selectivity in the second regime $\left(40 \mathrm{wt} \%<\omega_{\text {Zeo }}<80 \mathrm{wt} \%\right)$.
However, the maximum is not as distinct as in the case of the CO conversion but represents a plateau, and the plateau values do not differ much depending on the catalyst configuration. From this finding, the conclusion can be drawn that for an appropriate choice of the relative amounts of the two catalysts the product distribution is hardly influ enced by the catalyst configuration. It can be observed that the plateau in methanol and DME selectivity cannot reach the equilibrium. This can be attributed to the MTD kinetics implemented, which mirrors the activity of the H ZSM 5 as prepared in the present work (see Section 2.4). For comparison, when applying MTD kinetics from literature for a commercial H ZSM 5 catalyst (e.g. Ref. [55], see also Supporting Information S1.3) in the model, results close to the STD equilibrium are obtained (for CZA\&Z and CZA\&/Z, $S_{\mathrm{DME}}=91 \%$ instead of $S_{\mathrm{DME}}=80 \%$ and $S_{\mathrm{DME}}=71 \%$ at $\omega_{\mathrm{Zeo}}=20 \mathrm{wt} \%$, respectively). A further increase of the share of zeolite $\left(\omega_{\text {Zeo }}>80 \mathrm{wt} \%\right.$, third regime) results in a de crease of DME selectivity and increase of the methanol selectivity. In his regime, the $\mathrm{CO}_{2}$ selectivity decreases and becomes even negative. $\mathrm{CO}_{2}$ is produced via the WGS reaction (Eq. (3)) over CZA from CO and water, the latter being a side product of methanol dehydration (Eq. (4)) over the acidic catalyst. As described, a small amount of CZA results in less methanol being formed and, thus, less water being produced by its dehydration. In turn $\mathrm{CO}_{2}$ formation from $\mathrm{CO}$ via the WGS reaction is suppressed while methanol synthesis from $\mathrm{CO}_{2}$ (Eq. (2)) consumes $\mathrm{CO}_{2}$ 
resulting in sum in a consumption of $\mathrm{CO}_{2}$ in the overall system. The CZA\&Z and the CZA@Z systems allow for higher DME selectivity than the CZA $+\mathrm{Z}$ configuration, which is due to the enhanced hierarchical structure of the first two catalytic structures: in the CZA@Z system, the methanol produced in the core can only leave through the zeolite mi cropores (or defects) in the shell where it reacts to DME. In the CZA\&Z, the CZA is decorated around the zeolite crystallites, resulting in an increased synergy between the two kinds of active sites compared to $\mathrm{CZA}+\mathrm{Z}$ where aggregates of zeolite crystallites are embedded in a porous CZA matrix. The probability of methanol dehydration for CZA@ $\mathrm{Z}$ and CZA\&Z systems therefore is higher than in the CZA $+\mathrm{Z}$, where the two catalysts are more segregated due to the preparation concept (close vs. medium proximity of the two catalyst within the particle, see Supporting Information S1). The low CO conversion shown by CZA@Z is due to the mass transport resistance of the shell: it was observed (not shown here, see also [60]) that the zeolite covering the core is a very dense, intergrown layer, with low concentration of non zeolitic defect pores [60]. Based on that, the void fraction within the shell (zeolite intercrystalline porosity in the CZA@Z system) was estimated to be only 0.1 vol \% (see Table 4). This results in an enhancement of DME selectivity (low probability of methanol leaving the system without getting dehydrated) but, at the same time, hinders the diffusion of the reactants from the gas phase through the shell to the core (see below and [62]). In contrast, the zeolite intercrystalline pores in the zeolite matrix of the CZA\&Z and the resulting possibility of a more direct ac cess of the reactants from the gas phase to the CZA in the CZA $+\mathrm{Z}$ catalysts configuration allow for a higher $\mathrm{CO}$ conversion. As already discussed above, the benefit obtained by enhancing the proximity of the two catalysts and, consequently, the synergy between STM and MTD reactions in the CZA\&Z configuration is higher in comparison to the $\mathrm{CZA}+\mathrm{Z}$, as in the latter configuration the CZA and the zeolite have a less intimate contact. This results in the highest values of $\mathrm{CO}$ conver sion and DME selectivity for the CZA\&Z among the particulate systems investigated.

The diffusion limitation caused by the dense zeolite shell in the CZA@Z system was further investigated: in Fig. 3, the concentration of $\mathrm{CO}$, normalized to the concentration in the gas phase $\left(y_{\mathrm{CO}}\right)^{\prime}$ is shown versus the dimensionless length coordinate in the CZA\&Z system and the zeolite shell of the CZA@Z (thickness of $18 \mu \mathrm{m}$ was considered, corresponds to $\omega_{\text {Zeo }}=19 \mathrm{wt} \%$ ). A negligible gradient in the CO con centration was found for the CZA\&Z system $\left(y^{\prime}{ }_{\mathrm{CO}}\left(s^{\prime}=0\right)=0.99\right)$, which is to be expected in case of absent transport limitations. On the contrary, a significant gradient over the shell of the CZA@Z system $\left(y^{\prime} \mathrm{Co}\left(s^{\prime}=0\right)=0.89\right)$ was observed, which has to be linked to the diffusion hindering by the shell's mainly microporous structure.

These results are qualitatively in line with what was reported in the previous study of Ding, also discussing an increase of the CO conversion and a consequent decrease of DME selectivity with increasing inter and

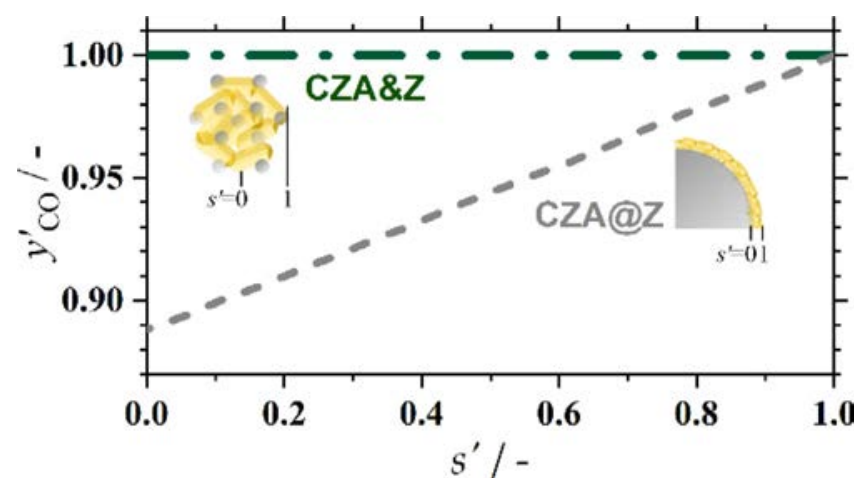

Fig. 3. Dimensionless CO concentration $\left(y^{\prime}{ }_{C O}\right)$ versus the dimensionless coordinate $\left(s^{\prime}\right)$ of the CZA\&Z and the zeolite shell of the CZA@Z system in a PFR. Reaction conditions: $p=40 \mathrm{bar}, T=250{ }^{\circ} \mathrm{C}, G H S V=2000 \mathrm{~mL} \mathrm{~h}^{-1} \mathrm{~g}_{\mathrm{CAT}}^{1}$. intracrystalline porosity of the zeolitic shell [62].

The different transport phenomena in the three particulate struc tures can also explain why the CO conversion exceeds the STM equili brium conversion $\left(X_{\mathrm{CO}, \mathrm{STM}}\right.$ equi. $=39.1 \%$ for the given process para meters) and reaches the maximum at different values of $\omega_{\text {Zeo }}$ : the STM equilibrium is overcome at 1,5 and $13 \mathrm{wt} \%$ and the CO conversion reaches its maximum at 40,30 and $17 \mathrm{wt} \%$ for the CZA\&Z, CZA $+\mathrm{Z}$ and CZA@Z systems, respectively. When the transport within the cat alyst is not hindered, a lower amount of CZA is sufficient to reach the maximum in $\mathrm{CO}$ conversion. In other words, to achieve both, high $\mathrm{CO}$ conversion and high DME selectivity, on the one hand it is necessary to enhance the accessibility of the CZA by the reactants and on the other hand an intimate contact between the two catalysts has to be given.

Simulation results at the same process conditions and GHSV were obtained for the layered systems in the $\mu \mathrm{CR}$, adapting the geometry described in Section 2.2. The results are shown in Fig. 4. In line with the CZA@Z system, for the CZA//Z, $\omega_{\text {Zeo }}$ of up to $60 \mathrm{wt} \%$ was considered.

In general, the trends of $\mathrm{CO}$ conversion and product selectivity ob tained for the particulate systems in the PFR can also be found for their coated counterparts in the $\mu \mathrm{CR}$. This is to be expected, as the influence of $\omega_{\text {Zeo }}$ on the STD reaction should not be affected by the kind of reactor considered. At low $\omega_{\text {Zeo }}(<10 \mathrm{wt} \%)$, the CO conversion is close to the STM equilibrium conversion, before increasing with $\omega_{\text {Zeo }}$ until a max imum is reached. Thereafter, CO conversion decreases with further increasing $\omega_{\text {Zeo }}$ even below the STM equilibrium conversion. In contrast to the results obtained for the particulate systems, the effect of $\omega_{\text {Zeo }}$ on the product selectivity is more pronounced for the coated systems in the $\mu$ CR: the increase of DME selectivity (resp. decrease of methanol se lectivity) with $\omega_{\text {Zeo }}$ is smaller and the maxima are more distinct in comparison to the broad plateau found for the particulate systems (see Fig. 2). DME selectivity versus CO conversion for the hybrid system in both, particulate and planar configuration (CZA\&Z and CZA\&/Z resp. $\mathrm{CZA}+\mathrm{Z}$ and CZA\#Z, see Fig. S6 in Supporting Information), show that the DME selectivity is barely affected by the implementation of the catalyst (particulate vs. planar).

The considerations made for the $\mathrm{CO}_{2}$ selectivity of the particulate catalysts are also valid for the planar systems: selectivity increases with $\omega_{\text {Zeo }}$ at low zeolite content before reaching the STD equilibrium $\left(S_{\mathrm{CO} 2 \text {,STD equi }}=27.5 \%\right)$. Starting from approx. $\omega_{\text {Zeo }}>80 \mathrm{wt} \% \mathrm{CO}_{2}$ selectivity decreases and becomes even negative due to the reaction system (see above).

The CZA@Z as packed bed in the PFR and its coated counterpart $\mathrm{CZA} / / \mathrm{Z}$ in the $\mu \mathrm{CR}$ perform differently in terms of CO conversion: the $\mathrm{CZA} / / \mathrm{Z}$ configuration shows rather similar $\mathrm{CO}$ conversion as the coated CZA\&/Z configuration. Thus, in contrast to the CZA@Z system, in the double layer configuration $\mathrm{CZA} / / \mathrm{Z}$ reactant diffusion is not hindered, which is due to the different morphology of the zeolite layers. CZA//Z is a printed double layer of CZA powder and zeolite crystallites whereas CZA@Z is a polycrystalline zeolite membrane enwrapping preformed CZA particles. This results in totally different porosity and pore size distribution (see Table 4). As a consequence of the larger porosity being in line with conclusions drawn for the CZA@Z system CO conversion in the CZA//Z system is not limited by reactant diffusion while the DME selectivity is not as high as for the coated CZA\&/Z of close proximity (see Fig. 4b) or the hierarchical structure in the CZA@Z with its dense zeolite shell. Once again, this is proving the opposing effect of the zeolite layer porosity on CO conversion (promoted by in tercrystalline porosity) and on the DME selectivity (promoted by the zeolite micropores).

In the $\mu \mathrm{CR}$, the maximum in CO conversion for all three catalyst configurations can be found at approx. $\omega_{\text {Zeo }}=40 \mathrm{wt} \%$, being similar or even slightly higher than for the particulate systems in the PFR. The maximum in DME selectivity is reached at $\omega_{\text {Zeo }}=80 \mathrm{wt} \%$ for both, $\mathrm{CZA} \& / \mathrm{Z}$ and CZA\#Z and at $\omega_{\mathrm{Zeo}}=56 \mathrm{wt} \%$ for the CZA//Z (at largest $\omega_{\text {Zeo }}$ value investigated). Even though the maximum values are similar, for the coated systems investigated, the plateaus in DME selectivity are 

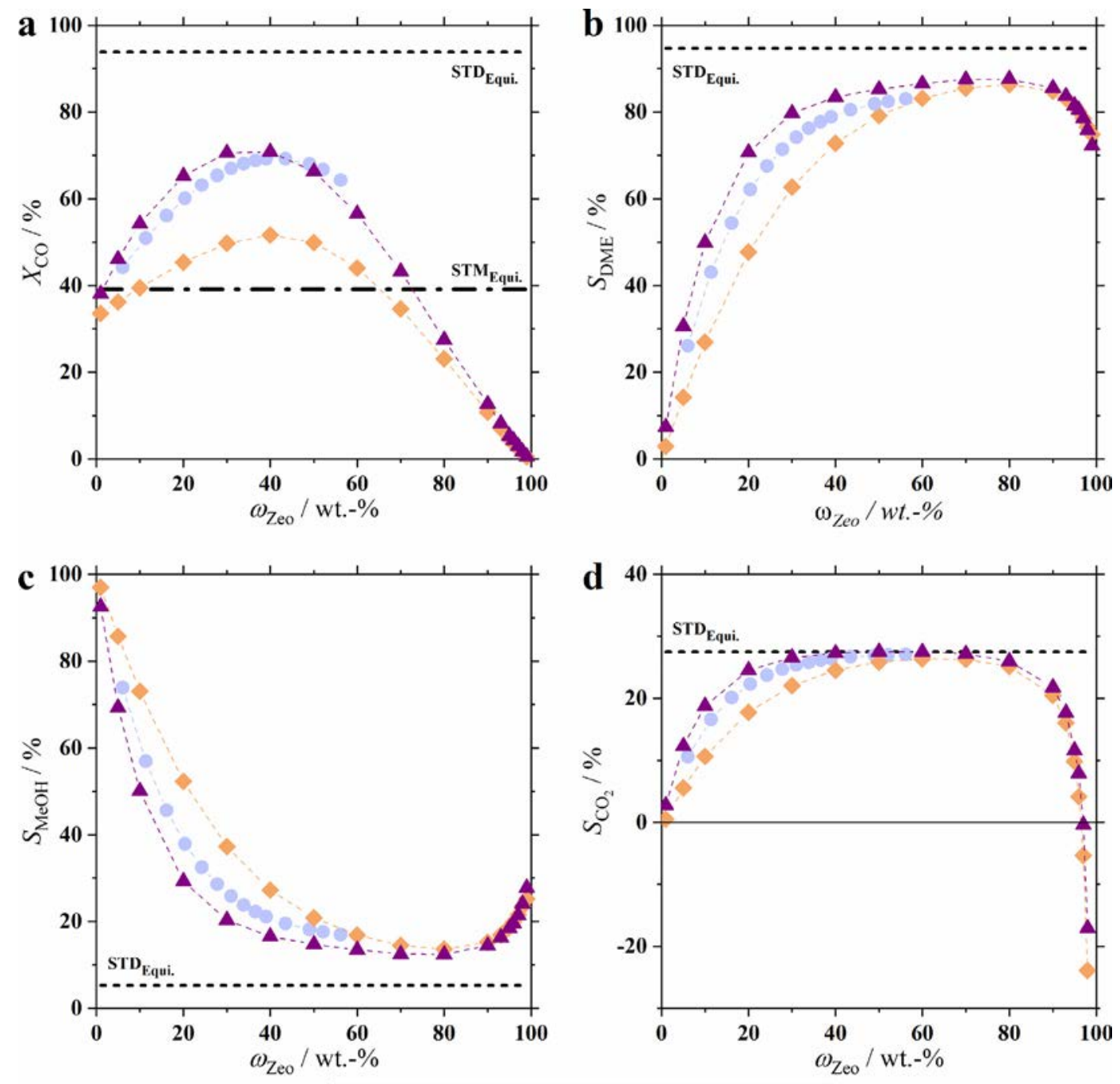

$-\mathrm{CZA} \& / \mathrm{Z} \rightarrow \mathrm{CZA \# Z} \odot \mathrm{CZA} / / \mathrm{Z}$

Fig. 4. a) CO-conversion $\left(X_{\mathrm{CO}}\right)$, b) DME-, c) methanol- and d) $\mathrm{CO}_{2}$-selectivity $\left(S_{\mathrm{DME}}, S_{\mathrm{MeOH}}\right.$ and $\left.S_{\mathrm{CO} 2}\right)$ for the layered catalyst systems CZA\&/Z, CZA\#Z and CZA//Z in a $\mu$-CR. Reaction conditions: $p=40 \mathrm{bar}, T=250^{\circ} \mathrm{C}, \mathrm{GHSV}=2000 \mathrm{~mL} \mathrm{~h}^{-1} \mathrm{~g}_{\mathrm{CAT}}^{1}$.

not as pronounced as for the particulate systems in the PFR.

In Fig. 5, both particulate and planar catalytic structures are com pared in terms of the DME yield. The hybrid structures with close proximity show the highest DME yield both as particulate (CZA\&Z) and coated (CZA\&/Z) system, while the yield of the latter one is comparable to the one obtained with the CZA//Z system.

For the particulate systems, the maximum DME yield is reached at $\omega_{\text {Zeo }}=40 \mathrm{wt} \%$ for CZA\&Z and CZA $+\mathrm{Z}$ and at $\omega_{\text {Zeo }}=22 \mathrm{wt} \%$ for the CZA@Z. For the coated systems, maximum yield is achieved likewise at approx. $\omega_{\text {Zeo }}=40 \mathrm{wt} \%$ for CZA\&/Z and CZA $/ / Z$, and at $50 \mathrm{wt} \%$ for CZA\#Z.

In general, the optimization of the catalyst configuration and com position depends on the target. This might either be DME yield (max imum product output) or maximum per pass CO conversion (decrease recycling). According to this simulation study, the particulate CZA\&Z as well as the coated CZA\&/Z and CZA//Z are promising in the PFR and the $\mu$ CR scenarios, respectively.

\subsection{Influence of reaction temperature}

The temperature of a chemical process can be chosen according to different criteria, such as finding the proper compromise between the highest yield to the desired product, potential thermodynamic limitations and the requirements predetermined by the catalyst (e.g. deactivation by sintering). As side reactions as well as catalyst deacti vation were not in the scope of this study, temperatures above $270{ }^{\circ} \mathrm{C}$ were not considered, as sintering of the CZA catalyst (deactivation) and the further reaction of the DME to hydrocarbons take place starting from approx. $280{ }^{\circ} \mathrm{C}$ and $300{ }^{\circ} \mathrm{C}$, respectively, as reported in literature $[38,40,70,71]$. In the following, the influence of the reaction tem perature on the STD reaction via the different bifunctional catalyst configurations is discussed in order to determine the optimum opera tional temperature for the materials considered.

Fig. 6 shows the CO conversion as a function of the reaction tem perature for the different particulate catalysts (Fig. 6a) as well as for the coated systems (Fig. 6b). For each catalyst, the composition in terms of $\omega_{\text {Zeo }}$ was defined based on the composition yielding maximum CO conversion as determined from the results of the simulations discussed above (Section 3.1): $\omega_{\text {Zeo }}\left(\mathrm{CZA \& Z)}=40\right.$ wt $\%, \quad \omega_{\text {Zeo }}$ $(\mathrm{CZA}+\mathrm{Z})=30 \mathrm{wt} \%, \omega_{\mathrm{Zeo}}(\mathrm{CZA} @ \mathrm{Z})=17 \mathrm{wt} \%, \omega_{\mathrm{Zeo}}(\mathrm{CZA} \&$ $/ \mathrm{Z})=40$ wt $\%, \quad \omega_{\mathrm{Zeo}}(\mathrm{CZA} / / \mathrm{Z})=43$ wt $\%$ and $\omega_{\mathrm{Zeo}}$

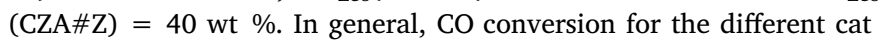
alyst configurations quantitatively order in accordance to what was reported in Section 3.1: the hybrid configurations with close proximity (CZA\&Z and CZA\&/Z) show the highest CO conversion throughout the temperature range investigated independent on the configuration 

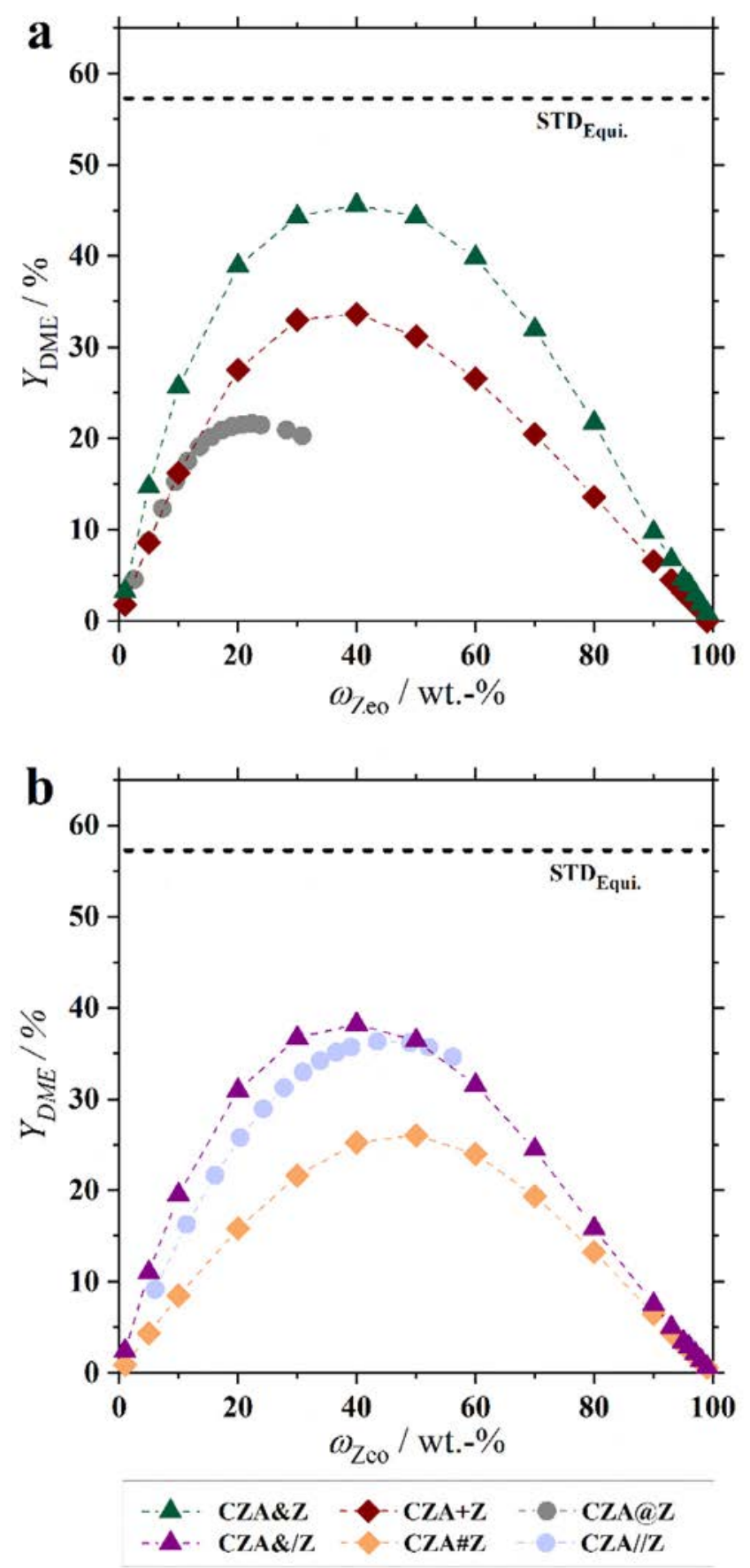

Fig. 5. DME-yield as a function of catalyst composition for all catalyst configurations studied a) particulate systems in a PFR and b) coated systems in a $\mu$ CR. Reaction conditions: $p=40$ bar, $T=250{ }^{\circ} \mathrm{C}, G H S V=2000 \mathrm{~mL} \mathrm{~h}^{-1} \mathrm{~g}_{\mathrm{CAT}}^{1}$.

(particulate or coated system). In general, at low reaction temperature, the CO conversion for all particulate systems investigated is below the STM equilibrium conversion, which is exceeded at about 230, 240 and $250{ }^{\circ} \mathrm{C}$ for the particulate systems CZA\&Z, CZA + Z and CZA@Z, re spectively. A comparable behavior can be observed for the coated systems, which allow to reach the thermodynamic equilibrium at about $235{ }^{\circ} \mathrm{C}$ for CZA\&/Z and CZA//Z and at about $245{ }^{\circ} \mathrm{C}$ for CZA\#Z. After exceeding the STM equilibrium conversion, for all catalysts $\mathrm{CO}$ con versions steadily increases with temperature until a maximum is reached with subsequent decrease of the conversion in line with the thermodynamic limitation of the STD reaction (see $X_{\mathrm{CO} \text {,STD equi. }}$ in Fig. 6).
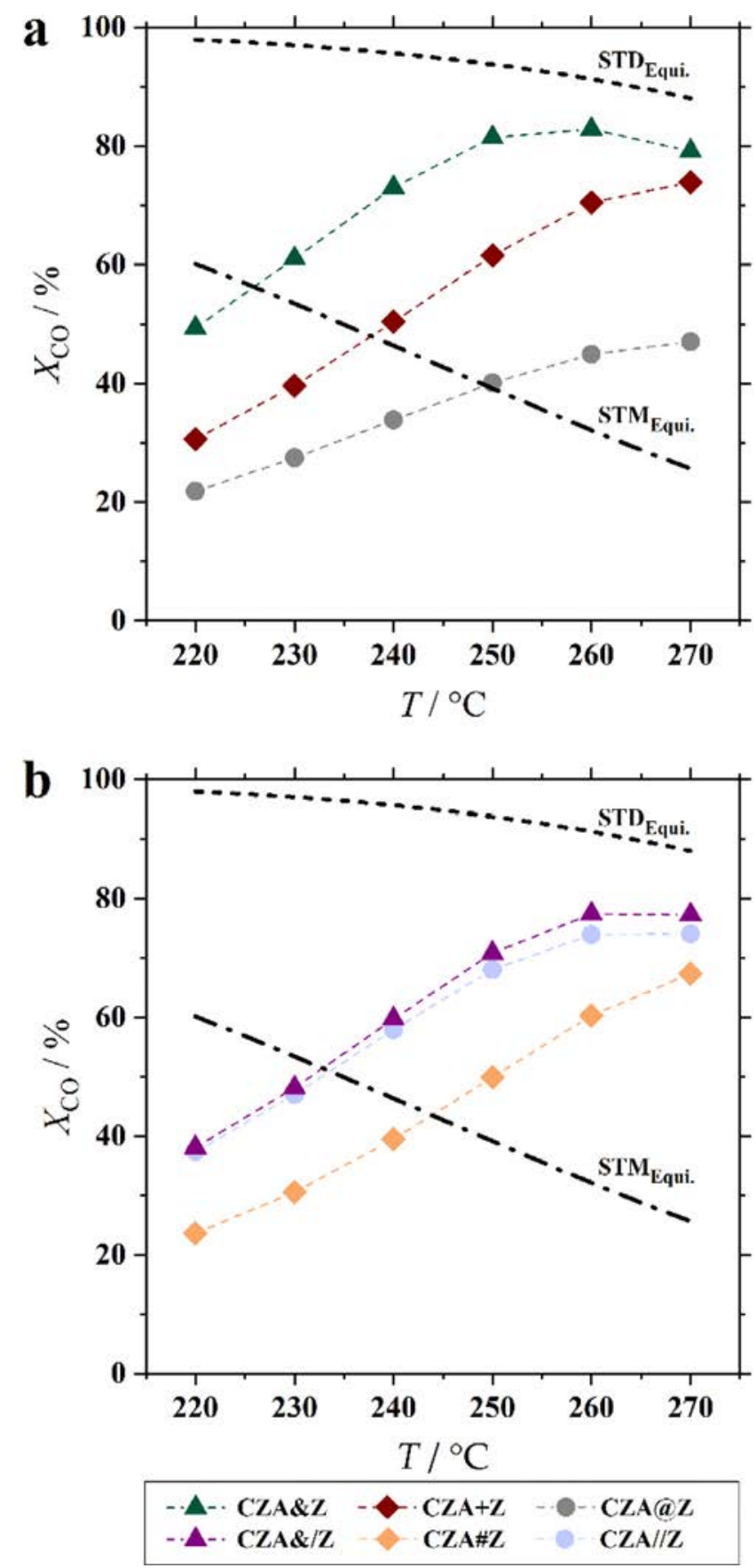

Fig. 6. CO-conversion as a function of the temperature for all catalyst configurations considered. a) particulate systems in a PFR and b) coated systems in a $\mu$-CR. (See text for accordant $\omega_{\text {Zeo }}$ applied). Reaction conditions: $p=40$ bar, GHSV $=2000 \mathrm{~mL} \mathrm{~h}^{-1} \mathrm{~g}_{\text {CAT }}^{1}$.

From these findings, it can be confirmed that the results shown in Section 3.1 (reaction temperature set to $250{ }^{\circ} \mathrm{C}$ ) are not affected by thermodynamics. In addition, for each catalyst configuration, an op timum reaction temperature resulting in a maximum of $\mathrm{CO}$ conversion can be determined: with $260^{\circ} \mathrm{C}$ for the particulate CZA\&Z $\left(X_{\mathrm{CO}}=83 \%\right)$ for the coated system CZA\&/Z $\left(X_{\mathrm{CO}}=77 \%\right)$ the highest $\mathrm{CO}$ conversion among the catalyst configurations and compositions studied would be expected. In the range investigated, the optimum temperature for the particulate systems CZA + Z and CZA@Z as well as for the planar systems CZA\#Z and CZA//Z is the maximum temperature of $270{ }^{\circ} \mathrm{C}$. Yet, for those systems somewhat lower $\mathrm{CO}$ conversions are reached as compared to CZA\&Z and CZA/\&Z (CZA+Z: $X_{\mathrm{CO}}=74 \%$, CZA@Z: 
$X_{\mathrm{CO}}=47 \%$ resp. CZA\#Z: $\left.X_{\mathrm{CO}}=67 \%, \mathrm{CZA} / / \mathrm{Z}: X_{\mathrm{CO}}=74 \%\right)$. For the $\mathrm{CZA} / / \mathrm{Z}$ and the CZA\&/Z, within the temperature range investigate, the CO conversion does not show a distinct maximum. However, as the highest values predicted are close to the STD equilibrium conversion at the highest temperature investigated, and as all three coated structures converged to similar values, the thermodynamic limitation is undeni able and, thus, further simulations at even higher temperatures were not considered here.

Concerning the DME yield (not shown) for the particulate systems maximum values were found at a reaction temperature of 260, 270 and $270{ }^{\circ} \mathrm{C}$ for CZA\&Z $\left(X_{\mathrm{CO}}=48 \%\right), \mathrm{CZA}+\mathrm{Z}\left(X_{\mathrm{CO}}=42 \%\right)$, and CZA@Z $\left(X_{\mathrm{CO}}=27 \%\right)$, respectively. For all coated catalyst configurations, the maximum DME yield is reached at $270{ }^{\circ} \mathrm{C}$, with $X_{\mathrm{CO}}=44 \%, 42 \%$ and $38 \%$ for $\mathrm{CZA} \& / \mathrm{Z}, \mathrm{CZA} / / \mathrm{Z}$ and $\mathrm{CZA} \# \mathrm{Z}$, respectively. In general, no deviation was observed between the temperatures resulting in max imum values of both, CO conversion and DME yield, except for the coated CZA\&/Z $\left(T_{\mathrm{X} \text { Co,max }}=260{ }^{\circ} \mathrm{C}, T_{\mathrm{Y} \text { DME, } \max }=270{ }^{\circ} \mathrm{C}\right)$ system. In summary, for each structure, the reaction temperature can be chosen in terms of the highest CO conversion without compromising the DME yield and vice versa.

This range of reaction temperatures is in agreement with the studies of Peláez e al. and Lu et al., who compared experimental data with results from modelling. Both studies highlight the importance of not exceeding a reaction temperature of $270{ }^{\circ} \mathrm{C}$ and concluded feasible reaction temperatures for the STD process are in the range of $250270{ }^{\circ} \mathrm{C}$, even though Lu et al., based on their simulation study, found a maximum in $\mathrm{CO}$ conversion and DME productivity at $T>280{ }^{\circ} \mathrm{C}[38,40]$.

In order to determine whether the CZA/zeolite ratio has an influ ence on the performance at variable reaction temperature, the CO conversion as a function of both, the temperature and $\omega_{\text {Zeo }}$ was ana lyzed in the present study. The results for the most promising candi dates, namely the particulate CZA\&Z and the coated CZA//Z systems, are shown in Fig. 7. At temperatures above $260{ }^{\circ} \mathrm{C}$, there is no distinct maximum in CO conversion with respect to $\omega_{\mathrm{Zeo}}$ : for these tempera tures, the $\mathrm{CO}$ conversion is not depending on the catalyst composition anymore. At lower temperatures, the maximum in $\mathrm{CO}$ conversion is at $\omega_{\text {Zeo }}=40 \mathrm{wt} \%$ for the particulate CZA\&Z. For the CZA $/ / \mathrm{Z}$ system, the maximum shifts from $\omega_{\text {Zeo }}=16 \mathrm{wt} \%\left(T=220^{\circ} \mathrm{C}, X_{\mathrm{CO}}=43 \%\right)$ up to $43 \mathrm{wt} \%\left(T=250{ }^{\circ} \mathrm{C}, X_{\mathrm{CO}}=69 \%\right)$ : if the temperature is increased, the CO conversion increases, too.

In summary, the CO conversion does not only depend on tempera ture, but also on the catalyst configuration and on its composition. For this reason, reaction temperature, configuration and composition of the catalyst have to be taken into account at the same time. Similar CO conversion can be achieved by different catalyst configurations and/or compositions and/or at different reaction temperatures. This fact could explain why Ramos et al. found that the performance of the STD was independent of the composition of the hybrid catalysts: the experi mental tests could have been limited by other process parameters, such as the temperature [24]. A reasonable criterion for the choice of both, the temperature and the $\omega_{\text {Zeo }}$, could be based on the synthesis costs of the catalyst with a certain composition versus the operational costs of the process at different temperatures. It should be emphasized, that the exothermicity of the reaction might result in temperature profiles along the reactor which can affect its performance. Even though this study assumes isothermal conditions in order to unravel the effect of the catalyst configuration, it should be emphasized, that the formation of a significant hot spot along the reactor can potentially lead to catalyst deactivation, especially of the more sensitive CZA catalyst. Besides, due to local higher temperatures, the overall reaction system is affected: while kinetics benefits from higher temperatures, the formation of the desired product is thermodynamically limited [15]. These aspects are less important for micro reactors which are well known for an efficient removal of the heat of reaction (see also Section 2.2). However, such optimizations were not among the objectives of this work, but call for
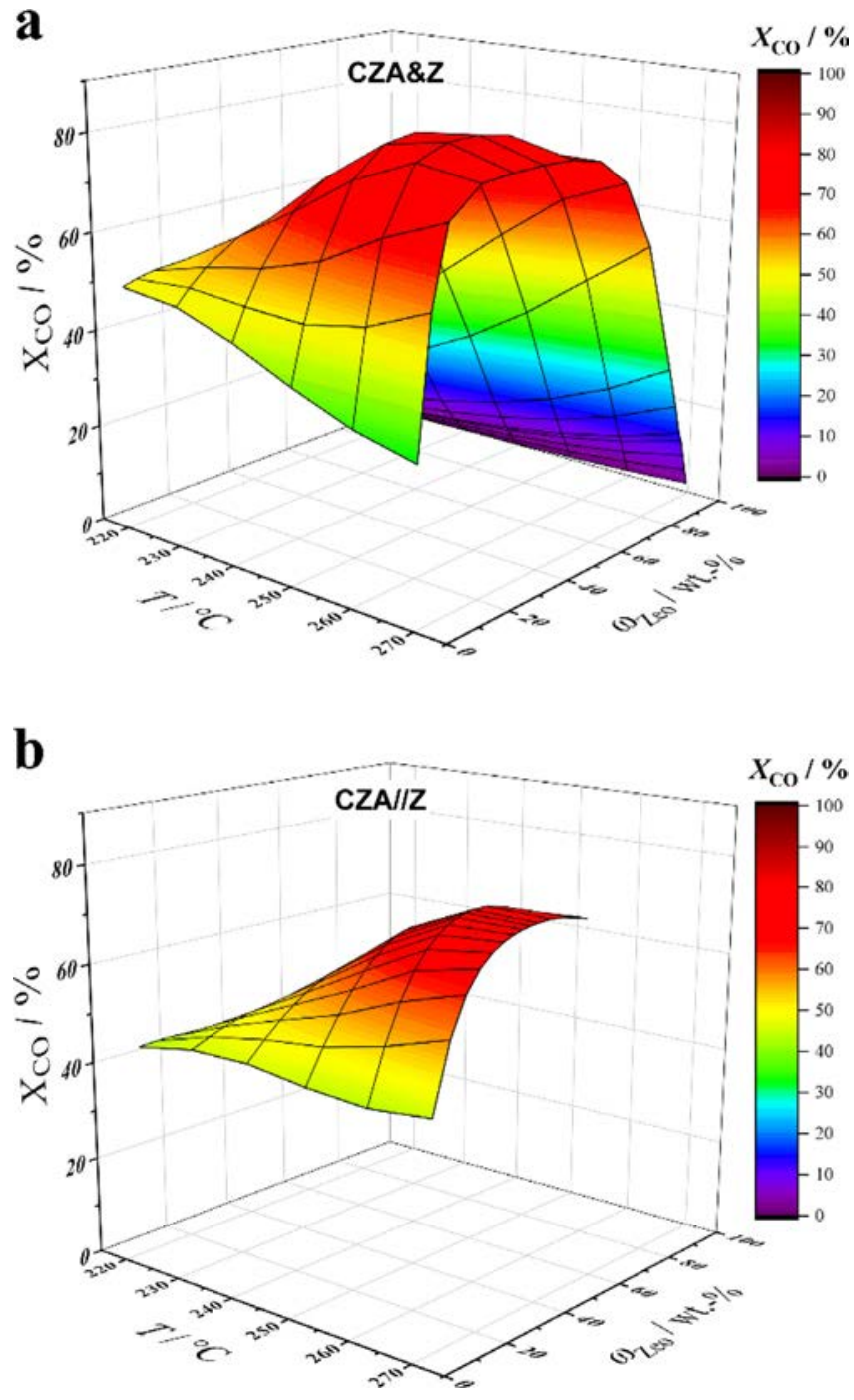

Fig. 7. CO-conversion as a function of temperature and $\omega_{\mathrm{Zeo}}$ for bifunctional catalysts. a) Particulate CZA\&Z in a PFR and b) coated CZA//Z in a $\mu C R$. Reaction conditions: $p=40$ bar, $T=250{ }^{\circ} \mathrm{C}, G H S V=2000 \mathrm{~mL} \mathrm{~h}^{-1} \mathrm{~g}_{\mathrm{CAT}}^{1}$.

further studies including experimental verification.

\subsection{Influence of the GHSV}

The GHSV, defined as the ratio between the total inlet volumetric flow and the mass of the catalyst, is an important parameter in a che mical process and for its scale up.

Simulation results of $\mathrm{CO}$ conversion versus $\mathrm{GHSV}$, at $250{ }^{\circ} \mathrm{C}$ and the optimum $\omega_{\text {Zeo }}$ in terms of CO conversion for each catalyst configuration (see Section 3.1), are shown in Fig. 8.

As expected, the CO conversion decreases with increasing GHSV. In addition, the ordering in the activity among the configurations in terms of CO conversion is consistent with other results obtained from simu lation discussed above (e.g. $X_{\mathrm{CO}}=f\left(\omega_{\mathrm{Zeo}}\right)$ ). For $G H S V$ values up to approx. $1000 \mathrm{~mL} \mathrm{~h}^{-1} \mathrm{~g}_{\mathrm{CAT}}^{1}$, for both, particulate and coated config urations, the reaction system is limited by the STD thermodynamic equilibrium and all systems reach $X_{\mathrm{CO}}=89 \%$. Starting from $1000 \mathrm{~mL} \mathrm{~h}^{-1} \mathrm{~g}_{\mathrm{CAT}}^{1}$, the CO conversion depends on the GHSV and, as described in the previous sections, the transport in each catalytic con figuration determines the performance of the process. At the highest GHSV investigated $\left(10 \mathrm{~L} \mathrm{~h}^{-1} \mathrm{~g}_{\mathrm{CAT}}^{1}\right)$, CO conversion of all the particulate and coated bifunctional catalysts converge to values well below the STM equilibrium, as the process is limited by the low residence time of 

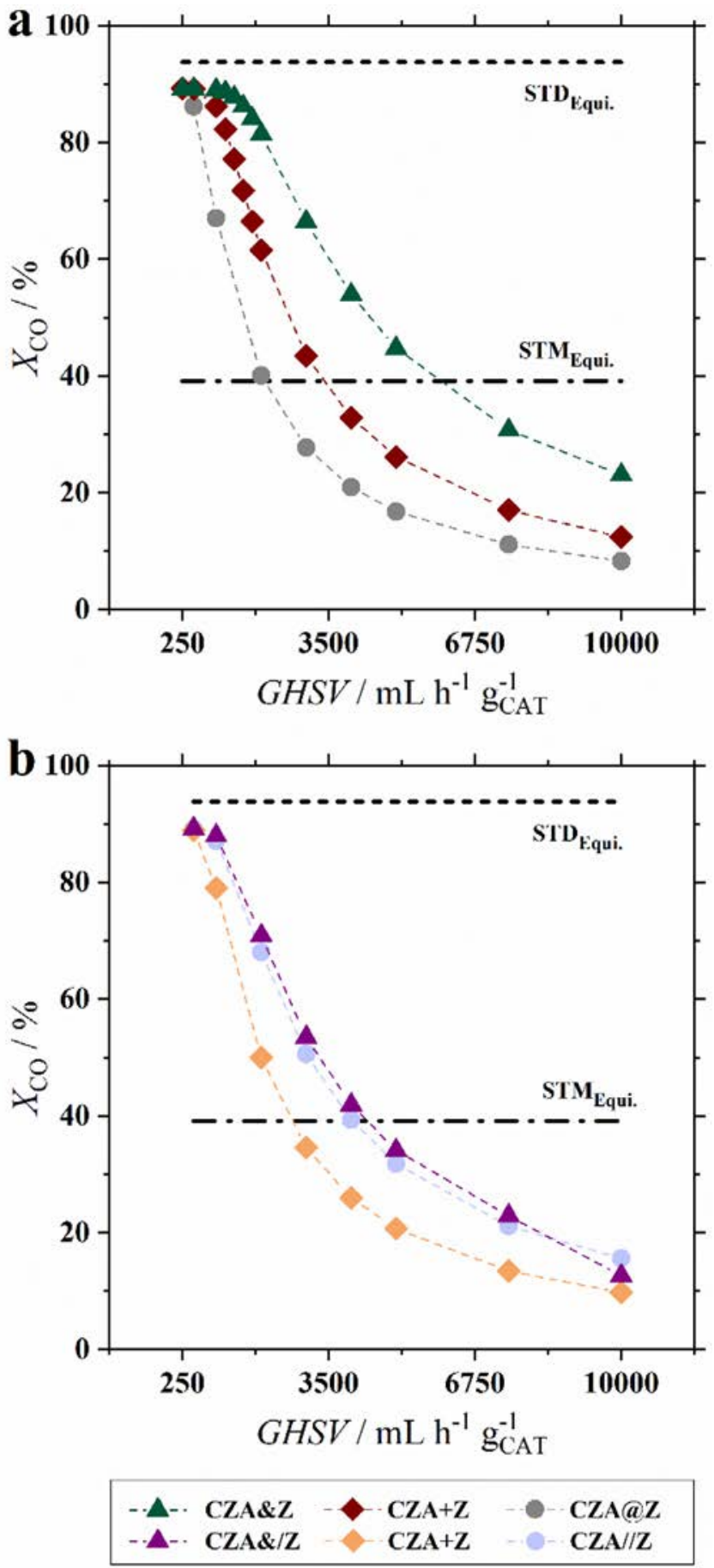

Fig. 8. CO-conversion as a function of the GHSV for the catalyst compositions studied. a) Particulate configuration in a PFR and b) coated configuration in a $\mu$-CR. (See text for accordant $\omega_{\text {Zeo }}$ ). Reaction conditions: $p=40$ bar, $T=250{ }^{\circ} \mathrm{C}$.

the reactants in the system.

The most suitable operational point regarding the GHSV for both, particulate and coated systems, is in the range of $10004000 \mathrm{~mL} \mathrm{~h}^{-1} \mathrm{~g}$ ${ }^{1}{ }_{\text {CAT }}$, in order to exclude the limitations given by thermodynamics and by the residence time. For this reason, as mentioned, the GHSV re ference for the simulation studies in this work was set to $2000 \mathrm{~mL} \mathrm{~h}^{-1}$ gCAT.
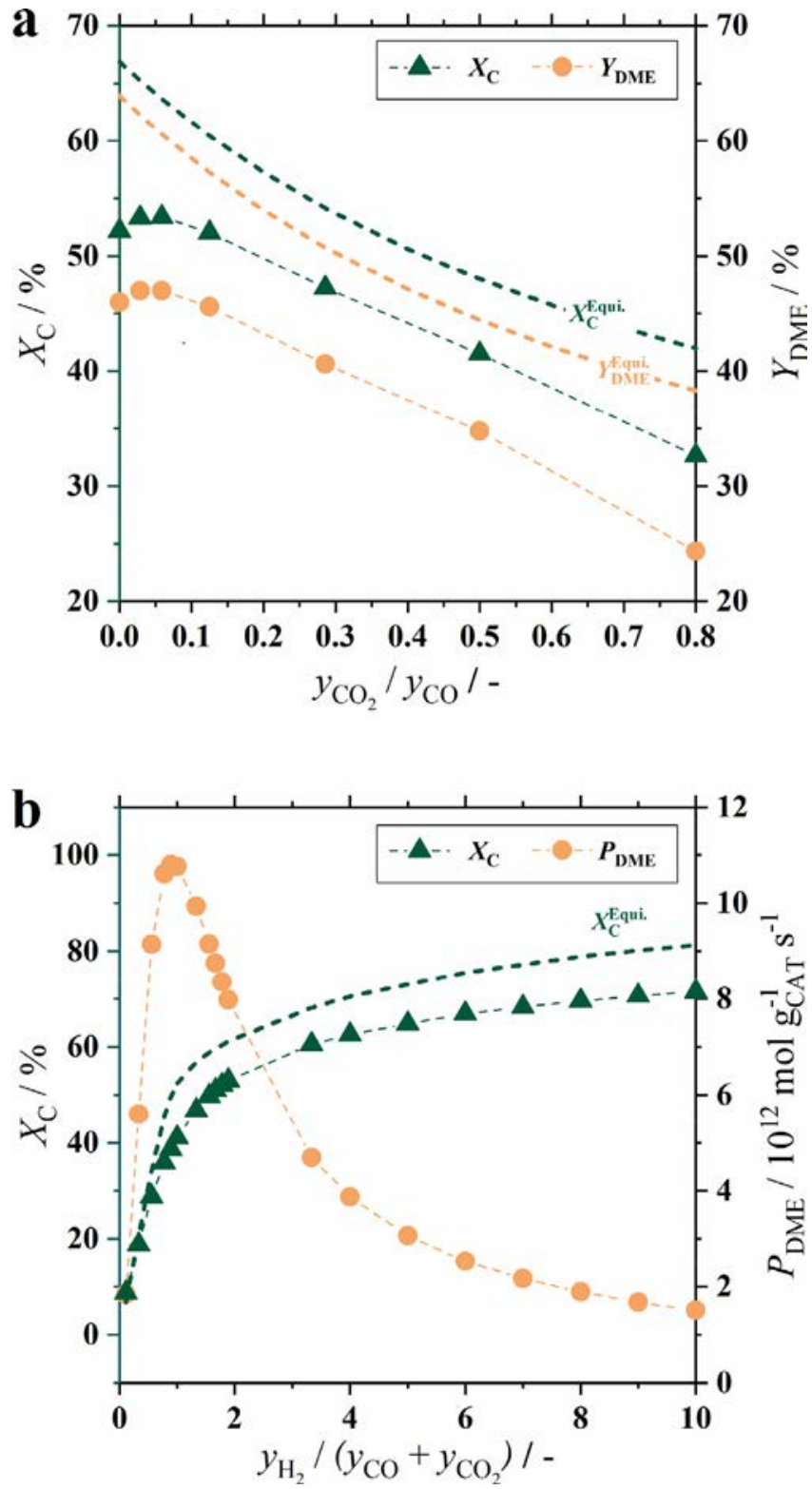

Fig. 9. Influence of the feed composition for the particulate CZA\&Z system on $\mathrm{CO}_{\mathrm{x}}$-conversion and a) DME-yield as a function of $y_{\mathrm{CO} 2} / y_{\mathrm{CO}}\left(\mathrm{H}_{2}=57.6 \mathrm{vol} \%=\right.$ const.) b) DME-productivity as a function of $y_{\mathrm{H} 2} /\left(y_{\mathrm{CO}}+y_{\mathrm{CO} 2}\right)\left(y_{\mathrm{CO} 2} / y_{\mathrm{CO}}=1 /\right.$ $8=$ const.) in a PFR. ( $\left.\omega_{\mathrm{Zeo}}=40 \mathrm{wt}-\%\right)$. Reaction conditions: $p=40$ bar, $T=250{ }^{\circ} \mathrm{C}, \mathrm{GHSV}=2000 \mathrm{~mL} \mathrm{~h}^{-1} \mathrm{~g}_{\mathrm{CAT}}^{1}$.

\subsection{Influence of the feed composition}

Feed composition is strongly influencing CO conversion and, thus, is a crucial factor for the STM resp. STD process. Moreover, in the context of the Power to $\mathrm{X}$ concept with its fluctuating renewable energy input, changes in feed composition are a relevant factor demanding for knowing the behavior of the reaction under different feed compositions. It is noteworthy to mention that this study aims at analyzing the be havior of the catalysts without taking into account their deactivation and response under dynamic operation, which has to be the objective of further studies.

In the frame of this work, the influence of the $y_{\mathrm{CO} 2} / y_{\mathrm{CO}}$ concentra tion ratio in the feed on the CO conversion and the DME yield as well as of the $y_{\mathrm{H} 2} /\left(y_{\mathrm{CO}}+y_{\mathrm{CO} 2}\right)$ concentration ratio on the $\mathrm{CO}_{\mathrm{x}}$ conversion $\left(X_{\mathrm{COx}}\right.$, Eq. $\left.(10)\right)$ and the DME productivity ( $P_{\mathrm{DME}}$, Eq. $\left.(14)\right)$ were stu died for one of the most promising candidate according to the findings 
discussed above, namely the particulate system with close proximity (CZA\&Z). The $\mathrm{CO}_{\mathrm{x}}$ conversion and DME yield/productivity compared to the maximum values given by thermodynamics $\left(X_{\mathrm{C} .}^{\text {Equi }}\right.$ and $\left.Y_{\mathrm{DME}}{ }^{\text {Equi }}\right)$ versus feed composition are shown in Fig. 9.

Fig. 9a shows the influence of the $y_{\mathrm{CO} 2} / y_{\mathrm{CO}}$ ratio on $\mathrm{CO}_{\mathrm{x}}$ conversion and DME yield, (feed concentration $\mathrm{H}_{2}: 57.6$ vol $\%=$ const., $\mathrm{N}_{2}$ : 10 vol $\%=$ const.). Starting from a pure $\mathrm{CO}$ feed, with increasing $\mathrm{CO}_{2}$ co feeding until 14.4 vol \% $\quad \mathrm{CO}_{2}$, at $y_{\mathrm{CO} 2} / y_{\mathrm{CO}}=0.06$ $\left(y_{\mathrm{CO}, \text { feed }}=1.8 \mathrm{vol} \%\right.$ and $\left.y_{\mathrm{CO}, \text { feed }}=30.6 \mathrm{vol} \%\right)$ both the $\mathrm{CO}_{\mathrm{x}}$ con version and the DME yield present a weak maximum. Further in creasing the $\mathrm{CO}_{2}$ content results in a decrease of both values. When feeding $\mathrm{CO}$ as the only carbon source, methanol can only be formed via Eq. (1). The water being produced by the subsequent dehydration step yielding DME (Eq. (4)) and the absence of $\mathrm{CO}_{2}$ shift the equilibrium of the WGS reaction (Eq. (3)) to the right resulting in less $\mathrm{CO}_{2}$ being produced via the STM reaction. In sum, the formation of methanol is limited by the absence of $\mathrm{CO}_{2}$ in the feed resulting in low values of $\mathrm{CO}_{\mathrm{x}}$ conversion and DME yield. When co feeding $\mathrm{CO}_{2}$, methanol can be formed from both, $\mathrm{CO}$ and $\mathrm{CO}_{2}$, which results in higher $\mathrm{CO}_{\mathrm{x}}$ conversion and DME yield until reaching a maximum. When the $y_{\mathrm{CO} 2} / y_{\mathrm{CO}}$ ratio exceeds 0.06 , the $\mathrm{CO}_{\mathrm{x}}$ conversion is negatively affected by the catalyst system, because the high concentration of $\mathrm{CO}_{2}$ promotes the formation of water via the reverse WGS, which eventually hinders DME dehy dration. This is in line with the studies of Peláez et al. and of $\mathrm{Ng}$ et al., who observed experimentally and by modelling the benefit of adding up to $46 \mathrm{vol} \%$ of $\mathrm{CO}_{2}$ in the feed gas, while for larger shares a decrease in conversion associated with an increase in methanol selectivity was detected [38,72].

Fig. 9b shows the influence of the ratio between $\mathrm{H}_{2}$ and $\mathrm{CO}_{\mathrm{x}} y_{\mathrm{H} 2} /$ $\left(y_{\mathrm{CO}}+y_{\mathrm{CO} 2}\right)\left(y_{\mathrm{CO} 2} / y_{\mathrm{CO}}=1 / 8=\right.$ const., 10 vol $\%$ of $\mathrm{N}_{2}$ in the feed $)$ on $\mathrm{CO}_{\mathrm{x}}$ conversion and DME productivity. The increase of the share of $\mathrm{H}_{2}$ in the feed results in a monotonic increase of the $\mathrm{CO}_{\mathrm{x}}$ conversion. In contrast, the DME productivity presents a maximum at $y_{\mathrm{H} 2} /$ $\left(y_{\mathrm{CO}}+y_{\mathrm{CO} 2}\right)=0.9$. According to literature, the $y_{\mathrm{H} 2} /\left(y_{\mathrm{CO}}+y_{\mathrm{CO} 2}\right)$ ratio should be at least equal to 1 in order to prevent deactivation of the catalyst caused by formation and deposition of coke [42]. The influence of the feed composition either on conversion, DME yield or DME pro ductivity is reported in several studies $[38,40,72]$ while mostly the $\mathrm{H}_{2}$ / $\mathrm{CO}$ ratio in the feed gas was studied. According to these studies, while the STM reaction is favored at $y_{\mathrm{H} 2} / y_{\mathrm{CO}}=2$, methanol dehydration is most active at $y_{\mathrm{H} 2} / y_{\mathrm{CO}}=1[38,40] . \mathrm{Ng}$ et al. studied the $y_{\mathrm{H} 2} /$ $\left(y_{\mathrm{CO}}+y_{\mathrm{CO} 2}\right)$ ratio and observed a maximum of the DME yield at about 1.6. A lower $\left.y_{\mathrm{H} 2} / y_{\mathrm{CO}}+y_{\mathrm{CO} 2}\right)$ ratio favors the removal of water via the WGS and thereby the formation of DME while a larger ratio has the opposite effect [72]. Hence, in this simulation study, the reference parameter set was defined as $y_{\mathrm{H} 2} /\left(y_{\mathrm{CO}}+y_{\mathrm{CO} 2}\right)=1.8$, with $\mathrm{CO}_{2}$ : $3.6 \mathrm{vol} \%\left(\mathrm{H}_{2}: 10 \mathrm{vol} \%\right)$ and $\mathrm{N}_{2}: 10 \mathrm{vol} \%$, which is a compromise between high productivity and the avoidance of coke formation and allows for a comparison with results reported in literature.

\section{Conclusions}

In the present study, catalyst systems of both particulate and planar (coated) configurations are compared in terms of their performance in the direct synthesis of DME from synthesis gas. The catalysts considered were obtained by combining $\mathrm{CuO} / \mathrm{ZnO} / \mathrm{Al}_{2} \mathrm{O}_{3}$ (CZA) with zeolite $\mathrm{H}$ ZSM 5 (Z) yielding hybrid systems with both close and medium proximity as well as structured systems. The different catalyst config urations were modelled and the effect of catalyst configuration and composition (i.e. zeolite mass fraction, $\omega_{\mathrm{Zeo}}$ ) as well as of the reaction parameters temperature, GHSV and feed composition in the PFR and in the $\mu \mathrm{CR}$ on CO conversion and products selectivity were studied via simulation. The results reveal that:

- At fixed operating conditions $\left(p=40\right.$ bar, $T=250{ }^{\circ} \mathrm{C}$, $G H S V=2000 \mathrm{~mL} \mathrm{~h}^{-1} \mathrm{~g}_{\mathrm{CAT}}^{1}$, feed composition: $\mathrm{H}_{2} / \mathrm{CO} / \mathrm{CO}_{2}=16 /$
8/1, 10 vol $\% \mathrm{~N}_{2}$ ), the CO conversion shows a maximum for each configuration at different $\omega_{\text {Zeo }}$. Furthermore, the sequence in max imum activity in terms of CO conversion is CZA@ $\mathrm{Z}<\mathrm{CZA}+\mathrm{Z}<\mathrm{CZA \& Z}$ and CZA\#Z $<\mathrm{CZA} / / \mathrm{Z} \leq \mathrm{CZA \&} / \mathrm{Z}$ for the particulate and layered systems, respectively. The close proxi mity of the two catalyst present in the hybrid CZA\&Z and the structure of the $\mathrm{CZA} / / \mathrm{Z}$ configurations improve both the $\mathrm{CO}$ con version and the DME selectivity in comparison to the $\mathrm{CZA}+\mathrm{Z}$ and the CZA\#Z systems of medium proximity.

- The different concept of the CZA@Z and the CZA//Z resp. their porosity and pore size distribution in the zeolite layer is the reason for the strong differences in their activity. The lower intercrystalline porosity within the dense H ZSM 5 shell of the CZA@Z hinders the diffusion of the reactants through the shell, which is not the case for the CZA//Z. The coated CZA//Z system does not face transport limitation and therefore allows for higher $\mathrm{CO}$ conversion. At the same time, the CZA@Z enables a higher DME selectivity, as the probability for methanol to diffuse through the intercrystalline pores without getting dehydrated at the active sites within the mi cropores is lower.

- The operational conditions (temperature and GHSV) were in vestigated in order to establish criteria for their choice for the STD process. In general, thermodynamic limitations were found for $T>260{ }^{\circ} \mathrm{C}$ and for GHVS $\leq 1000 \mathrm{~mL} \mathrm{~h}^{-1} \mathrm{~g}_{\mathrm{CAT}}^{1}$. The influence of the temperature on the catalyst performance is also dependent on $\omega_{\mathrm{Zeo}}$, which is to be taken into account when choosing the operation conditions.

- The influence of the $y_{\mathrm{CO} 2} / y_{\mathrm{CO}}$ as well as of the $\left.y_{\mathrm{H} 2} / y_{\mathrm{CO}}+y_{\mathrm{CO} 2}\right)$ feed ratio was investigated for the CZA\&Z configuration. The maximum in the DME yield and productivity were found at $y_{\mathrm{CO} 2} / y_{\mathrm{CO}}=0.06$ and $y_{\mathrm{H} 2} /\left(y_{\mathrm{CO}}+y_{\mathrm{CO} 2}\right)=1.6$, respectively.

- The hybrid particulate and layered systems of close proximity (CZA $\& \mathrm{Z}$ and CZA\&/Z) as well as the double layer system (CZA//Z) were found to be the most promising structures, especially for $\omega_{\text {Zeo }}=40 \mathrm{wt} \%$ when applied at $p=40$ bar, $T=260{ }^{\circ} \mathrm{C}$, GHSV $=2000 \mathrm{~mL} \mathrm{~h}^{-1} \mathrm{~g}_{\mathrm{CAT}}^{1}$, feed composition: $\mathrm{H}_{2} / \mathrm{CO} / \mathrm{CO}_{2}=16 /$ $8 / 1,10$ vol $\% \mathrm{~N}_{2}$.

In further investigations deactivation and the side reactions should also be taken into account.

\section{Declaration of Competing Interest}

The authors declare that they have no known competing financial interests or personal relationships that could have appeared to influ ence the work reported in this paper.

\section{Acknowledgements}

This work was supported by the German Research Foundation (DFG priority program 1570 "Porous Media with Defined Pore Structure in Process Engineering Modelling, Application, Synthesis“; Grant No. DI 696/ 93 and SCHW 478/23 3) and the Vector Foundation (“CO글

The authors would like to thank Ms. Aurina Arias Martinez from TU Clausthal for the synthesis of the catalysts and Dr. Albert G. F. Machoke for the characterization at the Fritz Haber Institute of the Max Planck Society. 


\section{References}

[1] J. Cook, N. Oreskes, P-.T. Doran, W.R. Anderegg, B. Verheggen, E.W. Maibach, J.S. Carlton, S. Lewandowsky, A. Skuce, S. Green, D. Nuccitelli, P. Jacobs, M. Richardson, B. Winkler, R. Painting, K. Rice, Consensus on consensus: a synthesis of consensus estimates on human-caused global warming, Environ. Res. Lett. 11 (2016) $1-7$.

[2] NASA - Global Climate Change, "Scientific Consensus: Earth's Climate is Warming," [Online]. Available: https://climate.nasa.gov/scientific-consensus/. [Accessed 27 $102019]$.

[3] United Nations, "Paris Agreement," 2015. [Online]. Available: https://unfccc.int/ sites/default/files/english paris agreement.pdf. [Accessed 2710 2019].

[4] Masson-Delmotte, Zhai, Pörtner, Roberts, Skea, Shukla, Pirani, Moufouma-Okia, Péan, Pidcock, Connors, Matthews, Chen, Zhou, Gomis, Lonnoy, Maycock, Tignor and Waterfield, "An IPCC Special Report on the impacts of global warming of $1.5^{\circ} \mathrm{C}$ above pre-industrial levels and related global greenhouse gas emission pathways, in the context of strengthening the global response to the threat of climate change, sustainable development,," Intergovernmental Panel on Climate Change, 2018.

[5] United Nations - Framework Convention on Climate Change, "Summary of GHC Emissions for European Union (KP)," [Online]. Available: https://di.unfccc.int/ gho profile annex1. [Accessed 2710 2019].

[6] Official Journal of the European Union, "DIRECTIVE 2009/28/EC OF THE EUROPEAN PARLIAMENT AND OF THE COUNCIL of 23 April 2009 on the promotion of the use of energy from renewable sources and amending and subsequently repealing Directives 2001/77/EC and 2003/30/EC (Text with EEA relevance)," 0506 2009. [Online]. Available: https://eur-lex.europa.eu/eli/dir/ 2009/28/oj. [Accessed 2510 2019].

[7] Official Journal of the European Union, "DIRECTIVE (EU) 2018/2001 OF THE EUROPEAN PARLIAMENT AND OF THE COUNCIL of 11 December 2018 on the promotion of the use of energy from renewable sources (recast) (Text with EEA relevance)," 2112 2018. [Online]. Available: https://eur-lex.europa.eu/eli/dir/ 2018/2001/oj. [Accessed 2510 2019].

[8] E.I. Koytsoumpaa, C. Berginsa, E. Kakarasa, The CO2 economy: Review of $\mathrm{CO} 2$ capture and reuse technologies, J. Supercrit. Fluids 132 (2018)

[9] German Federal Ministry of Education and Research, "Kopernikus-Projekte," [Online]. Available: https://www.kopernikus-projekte.de/en/projects/power2x. [Accessed 2710 2018].

[10] D. Ralph-Uwe, A. Friedemann, T. Pregger, Erzeugung alternativer fluessiger Kraftstoffe im zuku nftigen Energiesystem, Chem. Ing. Tech. 90 (1-2) (2018) 179-192.

[11] P. Schmidt, V. Batteiger, A. Roth, W. Weindorf, T. Raksha, Power-to-Liquids as Renewable Fuel Option for Aviation: A Review, Chem. Ing. Tech. 90 (1-2) (2018) 169-178.

[12] S.H. Park, S.H. Yoon, Injection strategy for simultaneous reduction of NOx and soot emissions using two-stage injection in DME fueled engine, Appl. Energy 143 (2015) 262-270.

[13] M. Mueller and U. Huebsch, "Dimethyl Ether," in Ullmann's Encyclopedia of Industrial Chemistry, Vol. 11.

[14] C. Arcoumanis, C. Bae, R. Crookes, E. Kinoshita, The potential of di-methyl ether (DME) as an alternative fuel for compression-ignition engines: A review, Fuel 87 (2008) 1014-1030.

[15] N.F. Ozturk, A.K. Avci, Intensified dimethyl ether production from synthesis gas with CO2, Chem. Eng. J. 370 (2019) 885-896.

[16] U. Tozar, A.K. Avci, Strategies for improving CO2 utilization in microchannel enabled production of dimethyl ether, Chem. Eng. Process. Process Intensif. (2020), https://doi.org/10.1016/j.cep.2020.107914.

[17] J. Erena, R. Garona, J.M. Arandes, A.T. Aguayo, J. Bilbao, Direct synthesis of dimethyl ether from $(\mathrm{H} 2+\mathrm{CO})$ and $(\mathrm{H} 2+\mathrm{CO} 2)$ feeds. Effect of feed composition, Int J. Chem. Reactor Eng. 3 (2005) A44.

[18] A. Behr, R. Kuhlmann, Chemische Umsetzung von Kohlendioxid, Chem. Ing. Tech 90 (2018) 593-601.

[19] F. Arena, K. Barbera, G. Italiano, G. Bonura, L. Spadaro, F. Frusteri, Synthesis, characterization and activity pattern of $\mathrm{Cu}-\mathrm{ZnO} / \mathrm{ZrO} 2$ catalysts in the hydrogenation of carbon dioxide to methanol, J. Catal. 249 (2007) 185-194.

[20] A. Karolevis, G. Galdames, J.C. Medina, C. Yévenes, Y. Barra, R. Jimenéz, Mechanism and structure sensitivity of methanol synthesis from $\mathrm{CO} 2$ over SiO2supported Cu nanoparticles, J. Catal. 369 (2019) 415-426.

[21] A. García-Trenco, A. Regoutz, E.R. White, D.J. Payne, M.S.P. Shaffer, C.K. Wiliams, PdIn intermetallic nanoparticles for the Hydrogenation of CO2 to Methanol, Appl. Catal., B 220 (2018) 9-18.

[22] R. Ahmad, M. Hellinger, M. Buchholz, H. Sezen, L. Gharnati, C. Wöll, J. Sauer, M. Döring, J. Grunwaldt, U. Arnold, Flame-made $\mathrm{Cu} / \mathrm{ZnO} / \mathrm{Al} 2 \mathrm{O} 3$ catalyst for dimethyl ether production, Catal. Commun. 43 (2014) 52-56.

[23] F. Dadgar, R. Myrstad, P. Pfeifer, A. Holmen, H.J. Venvik, Direct dimethyl ether synthesis from synthesis gas: The influence of methanol dehydration on methanol synthesis reaction, Catal. Today 270 (2016) 76-84

[24] F.S. Ramos, D. de Farias, L.E.P. Borges, J.L. Monteiro, M.A. Fraga, E.F. SousaAguiar, L.G. Appel, Role of dehydration catalyst acid properties on one-step DME synthesis over ohysical mixtures, Catal. Today 101 (2005) 39-44.

[25] A. García-Trenco, A. Martínez, A rational strategy for preparing Cu-ZnO/H-ZSM-5 hybrid catalystswith enhanced stability during the one-step conversion of syngas todimethyl ether (DME), Appl. Catal., A 493 (2015) 40-49.

[26] M. Cai, V. Subramaniana, V. Sushkevichb, V. Ordomskya, A. Khodakova, Effect of $\mathrm{Sn}$ additives on the CuZnAl-HZSM-5 hybrid catalysts for the direct DME synthesis from syngas, Appl. Catal., A 502 (2015) 370-379.
[27] M. Gentzen, W. Habicht, D.E. Doronkin, J.D. Grunwaldt, J. Sauer, S. Behrens, Bifunctional hybrid catalysts derived from $\mathrm{Cu} / \mathrm{Zn}$-based nanoparticles for singlestep dimethyl ether synthesis, Catal. Sci. Technol. 6 (2016) 1054-1063.

[28] A. Ateka, J. Erena, J. Bibao, A.T. Aguayo, Kinetic modeling of the direct synthesis of dimethyl ether over a CuO-ZnO-MnO/SAPO-18 catalyst and assessment of the $\mathrm{CO} 2$ conversion, Fuel Process. Technol. 181 (2018) 233-243.

[29] G. Yang, N. Tsubaki, J. Shamoto, Y. Yoneyama, Y. Zhang, Confinement effect and synergistic function of $\mathrm{H}-\mathrm{ZSM}-5 / \mathrm{Cu}-\mathrm{ZnO}-\mathrm{Al} 2 \mathrm{O} 3$ capsule catalyst for one-step controlled synthesis, J. Am. Chem. Soc. 132 (23) (2010) 8129-8136.

[30] R. Phienluphon, K. Pinkaew, G. Yang, J. Li, Q. Wei, Y. Yoneyama, T. Vitidsant, N. Tsubaki, Designing core $(\mathrm{Cu} / \mathrm{ZnO} / \mathrm{Al} 2 \mathrm{O} 3)$-shell (SAPO-11) zeolite capsule catalyst with a facile physical way for dimethyl ether direct synthesis from syngas, Chem. Eng. J. 270 (2015) 605-611.

[31] Y. Wang, W. Wang, Y. Chen, J. Maa, R. Li, Synthesis of dimethyl ether from syngas over core-shell structure catalyst CuO-ZnO-Al2O3@SiO2-Al2O3, Chem. Eng. J. 250 (2014) 248-256.

[32] M. Sánchez-Contador, A. Ateka, A.T. Aguayo, J. Bilbao, Direct synthesis of dimethyl ether from CO and CO2 over a core-shell structured CuO-ZnO-ZrO2@SAPO-11 catalyst, Fuel Process. Technol. 179 (2018) 258-268.

[33] R. Nie, H. Lei, S. Pan, S. Wang, J. Fei, Z. Hou, Core-shell structured CuO-ZnO@HZSM-5 catalysts for CO hydrogenation to dimethyl ether, Fuel 96 (2012) 419-425.

[34] K. Pinkaew, G. Yang, T. Vitidsant, Y. Jin, C. Zeng, Y. Yoneyama, N. Tsubaki, A new core-shell-like capsule catalyst with SAPO-46 zeolite shell encapsuated $\mathrm{Cr} / \mathrm{ZnOfor}$ the controlled tandem synthesis od dimethyl ether from syngas, Fuel 111 (2013) 727-732.

[35] R. Ahmad, D. Schrempp, S. Behrens, J. Sauer, M. Döring, U. Arnold, Zeolite-based bifunctional catalysts for the single step synthesis of dimethyl ether from CO-rich synthesis gas, Fuel Process. Technol. 121 (2014) 38-46.

[36] J.W. Jeong, C. Ahn, D.H. Lee, S.H. Um, J.W. Bae, Effects of Cu-ZnO Content on Reaction Rate for Direct Synthesis of DME from Syngas with Bifunctional $\mathrm{Cu}-\mathrm{ZnO}$ / gamma-Al2O3 Catalyst, Catal Lett 143 (2013) 666-672.

[37] H. Jiang, H. Bongard, W. Schmidt, F. Schüth, One-pot synthesis of mesoporous $\mathrm{Cu}$-gamma-Al2O3 as bifunctional catalyst for direct dimethyl ether synthesis, Microporous Mesoporous Mater. 164 (2012) 3-8.

[38] R. Peláez, P. Marín, S. Ordónez, Direct synthesis of dimethyl ether from syngas over mechanical mixtures of $\mathrm{CuO} / \mathrm{ZnO} / \mathrm{Al} 2 \mathrm{O} 3$ and gamma-Al2O3: Process optimization and kinetic modelling, Fuel Process. Technol. 168 (2017) 40-49.

[39] A. García-Trenco, A. Vidal-Moya, A. Martínez, Study of the interaction between components in hybrid CuZnAl/HZSM-5 catalysts and its impact in the syngas-toDME reaction, Catal. Today 179 (2012) 43-51.

[40] W.Z. Lu, L.H. Teng, W.D. Xiao, Simulation and experiment study of dimethyl ether synthesis from syngas in a fluidized-bed reactor, Chem. Eng. Sci. 59 (2004) 5455-5464.

[41] I. Sierra, J. Erena, A.T. Aguayo, M. Olazar, J. Bilbao, Deactivation Kinetics for Direct Dimethyl Ether Synthesis on a CuO-ZnO-Al2O3/ $\gamma$-Al2O3 Catalyst, Ind. Eng. Chem. Res. 49 (2010) 481-489.

[42] A.T. Aguayo, J. Erena, I. Sierra, M. Olazar, J. Bilbao, Deactivation and regeneration of hybrid catalysts in the single-step synthesis of dimethyl ether from syngas and CO2, Catal. Today 106 (2005) 265-270.

[43] J. Erena, I. Sierra, M. Olazar, A.G. Gayubo, A.T. Aguayo, Deactivation of a CuOZnO-Al2O3/gamma-Al2O3 Catalyst in the Synthesis of Dimethyl ther, Ind. Eng. Chem. Res. 47 (2008) 2238-2247.

[44] A. García-Trenco and A. Martínez, "Direct synthesis of DME from syngas on hybrid CuZnAl/ZSM-5 catalysts: New insights into the role of zeolite acidity," Appl. Catal., A, Vols. 411-412, pp. 170-179, 2012.

[45] A. García-Trenco, S. Valencia, A. Martínez, The impact of zeolite pore structure on the catalytic behavior of $\mathrm{CuZnAl} /$ zeolite hybrid catalysts for the direct DME synthesis, Appl. Catal., A 468 (2013) 102-111.

[46] A. García-Trenco, A. Martínez, The influence of zeolite surface-aluminum species on the deactivation deactivationof $\mathrm{CuZnAl} /$ zeolite hybrid catalysts for the direct DME synthesis, Catal. Today 277 (2014) 144-153.

[47] A.T. Aguayo, J. Erena, D. Mier, J.M. Arandes, M. Olazar, J. Bilbao, Kinetic Modeling of Dimethyl Ether Synthesis in a Single Step on a CuO-ZnO-Al2O3/gamma-Al2O3 Catalyst, Ind. Eng. Chem. Res. 46 (2007) 5522-5530.

[48] J. Erena, R. Garona, J.M. Arandes, A.T. Aguayo, J. Bilbao, Effect of operating conditions on the synthesis of dimethyl ether over a CuO-ZnO-Al2O3/NaHZSM-5 bifunctional catalyst, Int. J. Chem. Reactor Eng. 107 (2005) 467-473.

[49] M. Cai A. Palcic V. Subramanian M. S., O. Ersen, V. Valtchev, V. V. Ordomsky and A. Y. Khodakov, Direct dimethyl ether synthesis from syngas on copper-zeolite hybrid catalysts with a wide range of zeolite particle sizes J. Catal. 3382016227238.

[50] G.H. Graff, E.J. Stamhuis, A.A.C.M. Beenackers, Kinetics of low-pressure Methanol Synthesis, Chem. Eng. Sci. 43 (12) (1988) 3185-3195.

[51] K.M. Vanden Bussche, G.F. Froment, A steady-state kinetic model for methanol synthesis and the water gas shift reaction on a commercial $\mathrm{Cu} / \mathrm{ZnO} / \mathrm{Al} 2 \mathrm{O} 3$ Catalyst, J. Catal. 161 (156) (1996) 1-10.

[52] C. Seidel, A. Jörke, B. Vollbrecht, A. Seidel-Morgenstern, A. Knienle, Kinetic modeling of methanol synthesis from renewable resources, Chem. Eng. Sci. 175 (2018) $130-138$.

[53] G.H. Graff, H. Scholtens, E.J. Stamhius, A.A.C.M. Beenackers, Intra-particle diffusion limitations in the low-pressure Methanol Synthesis, Chem. Eng. Sci. 45 (4) (1990) 773-783.

[54] B.J. Lommerts, G.H. Graaf, A.A.C.M. Beenackers, Mathematical modeling of internal mass transport limitations in methanol synthesis, Chem. Eng. Sci. 55 (2000) 5589-5598.

[55] G. Bercic, J. Levec, Catalytic Dehydration of Methanol to Dimethyl Ether. Kinetic Investigation and Reactor Simulation, Ind. Eng. Chem. Res. 32 (1993) 2478-2484. 
[56] Y. Tavan, S.H. Hosseini, M. Ghavipour, M.R.K. Nikou, A. Shariati, From laboratory experiments to simulation studies of methanol dehydration to produce dimethyl ether-Part I: Reaction kinetic study, Chem. Eng. Process. 73 (2013) 144-150.

[57] A. Hadipour, M. Sohrabi, Kinetic parameters and dynamic modeling of a reactor for direct conversion of synthesis gas to dimethyl ether, J. Ind. Eng. Chem. 13 (4) (2007) 558-565.

[58] R. Peláez, P. Marín, F.V. Diéz, S. Ordónez, Direct synthesis of dimethyl ether in multi-tubular fixed-bed reactors: 2D multi-scale modelling and optimum design, Fuel Process. Technol. 174 (2018) 149-157.

[59] Y.I. Pyatnitskii, E. Strizhak, N.K. Lunev, Kinetic modeling for the conversion of synthesis gas to dimethyl ether on a mixed $\mathrm{Cu}-\mathrm{Zn}$-Al2O3 catalyst with gammaAl2O3, Theor. Exp. Chem. 45 (2009) 325-330.

[60] G. Baracchini, A.G.F. Machoke, M. Klumpp, R. Wen, P. Arnold, W. Schwieger, R. Dittmeyer, Structured catalysts for the direct synthesis of dimethyl ether from synthesis gas: a comparison of core@shell versus hybrid catalyst configuration, Catal. Today 342 (2020) 46-58.

[61] W. Ding, M. Klumpp, S. Lee, S. Reuß, S.A. Al-Thabaiti, P. Pfeifer, W. Schwieger, R. Dittmeyer, Simulation of one-stage dimethyl ether synthesis over a core-shell catalyst, Chem. Ing. Tech. 87 (6) (2015) 702-712.

[62] W. Ding, Simulation-Assisted Design of Polycrystalline Zeolite Catalysts Dissertation, Karlsruhe Institute of Techology, Karlsruhe, 2015.

[63] C. Baerlocher, L.B. McCusker, D.H. Olson, Atlas of Zelte Frameworks Types, Elsevier B. V, Amsterdam, 2007.
[64] S. Tauro, One-Step Synthesis of Dimethyl Ether Using Microreactors. Dissertation. Karlsruhe Institute of Techology, Aachen: Shaker, 2014.

[65] F. Hayer, H. Bakhtiary-Davijany, R. Myrstad, A. Holmen, P. Pfeifer, H.J. Venvik, Characteristics of integrated micro packed bed reactor-heatexchanger configurations in the direct synthesis of dimethyl ether, Chem. Eng. Process. 70 (2013) 77-85.

[66] J. Knochen, R. Güttel, C. Knobloch, T. Turek, Fischer-Tropsch synthesis in millistructured fixed-bed reactors: Experimental study and scale-up considerations, Chem. Eng. Process. 49 (2010) 958-964.

[67] J. Némethné, M. Benke, Microreactors: a new concept for chemical synthesis and technological feasibility, Mater. Sci. Eng. 39 (2014) 89-101.

[68] VDI-Gesellschaft Verfahrenstechnik und Chemieingenieurwesen, VDI-Wärmeatlas, Section G, Heidelberg: Springer-Verlag, 2013.

[69] W. He, L. Weiqiang, J. Dickerson, Gas Transport in Solid Oxide Fuel Cells, Chap. 2, Springer, Heidelberg, 2014.

[70] L. Li, D. Mao, J. Xiao, X. Guo, J. Yu, Facile preparation of highly efficient CuO-ZnOZrO2/HZSM-5 bifunctional catalyst for one-step CO2 hydrogenation to dimethyl ether: Influence of calcination temperature, Chem. Eng. Res. Des. 11 (2016) $100-108$.

[71] S. Lee, M. Gogate, J. Kulik, Methanol-to -Gasoline vs. DME-to-Gasoline II. Process comparison and analysis, Fuel Sci. Technol. Int. 13 (8) (2007) 1039-1057.

[72] K.L. Ng, D. Chadwick, B.A. Toseland, Kinetics and modelling of dimethyl ether synthesis from synthesis gas, Chem. Eng. Sci. 54 (1999) 3587-3592. 
Karlsruher Institut für Technologie

\section{Repository KITopen}

Dies ist ein Postprint/begutachtetes Manuskript.

Empfohlene Zitierung:

Baracchini, G.; Klumpp, M.; Arnold, P.; Dittmeyer, R.

Direct synthesis of dimethyl ether: A simulation study on the influence of the catalyst configuration.

2020. The chemical engineering journal, 396, 125155.

doi: $\underline{10.5445 / / R / 1000119321}$

Zitierung der Originalveröffentlichung:

Baracchini, G.; Klumpp, M.; Arnold, P.; Dittmeyer, R.

Direct synthesis of dimethyl ether: A simulation study on the influence of the catalyst configuration.

2020. The chemical engineering journal, 396, 125155.

doi:10.1016/j.cej.2020.125155

Lizenzinformationen: CC BY NC ND-Lizenz 